Contents lists available at www.ijpba.in

International Journal of Pharmaceutical and Biological Science Archive

PubMed (National Library of Medicine ID: 101738825)

Index Copernicus Value 2017: 71.80

Volume 7 Issue 2; March-April; 2019; Page No. 208-246

\title{
“FORMULATION AND EVALUATION OF BUCCAL FILMS OF SAXAGLIPTIN"
}

\author{
Mr. Vipul Pandit
}

PG Research Scholar, Department of Pharmaceutics, Sharda School of Pharmacy, Pethapur, Gandhinagar, Gujarat

\section{Mr. Vijay Patel}

Assistant Professor, Department of Pharmaceutics, Sharda School of Pharmacy, Pethapur, Gandhinagar, Gujarat

\section{ABSTRACT}

Objective: Saxagliptin is an orally anti-diabetic drug. It has an oral bioavailability of $50 \%$ due to first pass hepatic metabolism. To achieve sustained action of drug, reduce dosing frequency, bypass the hepatic first pass effect and improve bioavailability, buccal films formulation was planned.

Methods: Compatibility of the drug with the excipients was studied with the help of FTIR. $2^{3}$ factorial design was planned using concentration of Sodium alginate, concentration of Chitosan and PEG 400. Solvent casting method was used for the fabrication of films. Weight, thickness, surface $\mathrm{pH}$, mucoadhesive strength, in vitro residence time, \% swelling and \% drug release were evaluated for the prepared film formulations.

Results: All the films were found have surface $\mathrm{pH}$ close to neutral $\mathrm{pH}$ and were found to have content uniformity. Mucoadhesive strength was found to increase with increase in concentration of Chitosan. Drug release is more controlled by the high swelling film formers than sodium alginate. Among the film formers, though swelling is more, \% drug release is also more from sodium alginate and Chitosan films because of its ionic nature and more solubility.

Conclusion: Because of high mucoadhesive strength and more \% drug release, combination of Sodium alginate with Chitosan film formulations was selected.

Key Words: Saxagliptin, Buccal films

\section{INTRODUCTION}

\subsection{Introduction of Drug Delivery System}

\subsubsection{Introduction of Buccal Drug delivery system ${ }^{(1,2)}$}

Bioadhesive medication conveyance details were presented in 1947 when gum tragacanth was blended with dental glue powder to apply penicillin to the oral mucosa. As of late conveyance of remedial specialists by means of Mucoadhesive medication conveyance framework has turned out to be very fascinating. Certain medications have absence of adequacy because of diminished bioavailability, GI bigotry, flighty and inconsistent ingestion or pre-fundamental end of other potential course for organization. The ongoing advancement in the medication conveyance has heightened the examination of mucosal medication conveyance. Such course incorporates oral, buccal, visual, nasal and pneumonic courses and so forth. Mucoadhesive medication conveyance frameworks are conveyance frameworks, which used the property of bioadhesion of specific polymers, which end up cement on hydration and henceforth can be utilized for focusing on a medication to specific area of the body for expanded timeframe. The capacity to keep up a conveyance framework at a specific area for an expanded timeframe has extraordinary interest for both neighborhood and in addition fundamental medication bioavailability.

Buccal courses of medication conveyance offer an extensive number of points of interest over the other course of medication organization for foundational tranquilize conveyance, for example, sidestep of first 
pass impact and medication specifically conveyed to fundamental dissemination, shirking of prefoundational disposal inside the GI tract. These components make the buccal medication conveyance an extremely alluring and attainable site for fundamental medication conveyance.

Considering alternate courses of medication conveyance which has low patient consistence, for example, rectal, vaginal, sublingual and nasal medication conveyance for controlled discharge, the buccal mucosa has rich blood supply and it is moderately penetrable. The analyst amass has been examined that nasal hole as a site for foundational sedate conveyance however the potential bothering and the irreversible harm to the ciliary activity of the nasal pit from ceaseless use of nasal measurement shape put this course in the second line of medication conveyance. Despite the fact that the rectal, vaginal, and visual mucosa all offer certain focal points, yet the poor patient worthiness related with these destinations renders them saved for neighborhood applications as opposed to fundamental medication organization. The buccal have capacity to keep up a conveyance framework at a specific area for a broadened timeframe has incredible interest for both neighborhood and also foundational sedate bioavailability. The buccal mucosa are wealthy in blood supply and ingestion happen at this place is effective, and furthermore the course likewise giving fast medication transport to the fundamental flow and staying away from corruption by gastro-intestinal compounds and first pass hepatic digestion.

Besides, the oral hole is effectively open for self pharmaceutical and the organization medicate is to be immediately ended if there should arise an occurrence of poisonous quality by expelling the measurements frame from buccal depression. Buccal mucosa is less penetrable than the sublingual site which settles on it more suitable decision of site whenever delayed medication conveyance.

\subsubsection{Oral Mucosa ${ }^{(3)}$}

The aggregate region of the oral depression is $100 \mathrm{~cm}^{2} .33 \%$ is the buccal surface, or, in other words an epithelium of around $0.5 \mathrm{~mm}$ thickness. The primary job of oral mucosa is insurance of tissue fundamental. Lipid based porousness hindrances in epithelium layer shield the tissues from liquid misfortune and furthermore from the assault of hurtful natural specialists like microbial poisons, antigens, cancer-causing agents, catalysts and so on.

Oral epithelium multiplication time is 5-6 days. Oral cavity is that territory of mouth depicted by the lips, cheeks, hard sense of taste, and delicate sense of taste and floor of mouth. The oral cavity comprises of two areas. External oral vestibule which is limited by cheeks, lips, teeth and gingival (gums). Oral pit appropriate which stretches out from teeth and gums back to the fixtures (which prompt pharynx) with the rooftop involving the hard and delicate sense of taste. The tongue ventures from the floor of the cavity.

\subsubsection{Functions of Oral Cavity ${ }^{(4)}$}

$\checkmark$ Serving in chewing and mixing of food.

$\checkmark$ Helps to lubricate bolus the food matter

$\checkmark$ To discover the ingested material by and taste buds of tongue.

$\checkmark$ To start the carbohydrate and fat metabolism.

$\checkmark \quad$ As a portal for intake of food material and water.

$\checkmark \quad$ To aid in speech and breathing process.

\subsubsection{Mucus Membranes ${ }^{(5)}$}

Organic liquid films are the soaked surfaces covering the dividers of various body pits, for instance, the gastrointestinal and respiratory tracts. They contain a connective tissue layer (the lamina propria) above which is an epithelial layer, the surface of which is made saturated commonly by the proximity of a natural liquid layer. The epithelia may be either single layered (e.g. the stomach, nearly nothing and stomach related organs and bronchi) or multilayered/stratified (e.g. in the throat, vagina and cornea). The past contain glass cells which transmit natural liquid clearly onto the epithelial surfaces; the last contain, or are coterminous tissues containing, specific organs, for instance, salivary organs that release organic liquid onto the epithelial surface. Organic liquid is accessible either as a gel layer adherent to the mucosal surface or as 
a luminal dissolvable or suspended casing. The noteworthy parts of all organic liquid gels are mucin glycoproteins, lipids, inorganic salts and water, the last speaking to over $95 \%$ of their weight, making them an outstandingly hydrated structure. The genuine components of natural liquid are that of affirmation and oil.

\subsubsection{Mechanisms of Mucoadhesion ${ }^{(6)}$}

The system of mucoadhesion is by and large separated into two stages: the contact organizes and the union stage. The main stage is described by the contact between the mucoadhesive and the bodily fluid film, with spreading and swelling of the plan, starting its profound contact with the bodily fluid layer.

\subsubsection{Mucoadhesion Theories ${ }^{(7,8)}$}

Mucoadhesion is a complex process and numerous theories have been proposed to explain the mechanisms involved. These theories include mechanical interlocking, electrostatic, diffusion interpenetration, adsorption and fracture processes.

$\rightarrow$ Wetting Theory

$\rightarrow$ Diffusion Theory

$\rightarrow$ Fracture Theory

$\rightarrow$ The Electronic Theory

$\rightarrow$ The Adsorption Theory

\subsubsection{Need of Mucoadhesive ${ }^{(9)}$}

$\checkmark$ Controlled release.

$\checkmark \quad$ Target \& localized drug delivery.

$\checkmark \quad$ By pass first pass metabolism.

$\checkmark$ Avoidance of drug degradation.

$\checkmark$ Prolonged effect.

$\checkmark \quad$ High drug flux through the absorbing tissue.

$\checkmark$ Reduction in fluctuation of steady state plasma level.

\subsubsection{Potential advantages of Buccal Drug Delivery System ${ }^{(10)}$}

$\checkmark$ Less enzymatic activity.

$\checkmark \quad$ Avoid first pass metabolism.

$\checkmark$ High permeability so, more bioavailability.

$\checkmark$ Significant reduction in a dose.

$\checkmark$ Rich blood supply.

$\checkmark$ Easily accessible for self-medication.

$\checkmark$ Systemic adsorption is rapid.

$\checkmark \quad$ It offers a passive system of drug absorption and does not require any activation.

$\checkmark \quad$ It can be terminated in case of toxicity just by removing the dosage form from buccal cavity.

$\checkmark$ Drugs, which are unstable in the acidic environment, are destroyed by enzymatic or this route can administer alkaline environment of intestine.

\subsubsection{Limitation of buccal drug delivery system ${ }^{(10)}$}

$\checkmark$ Drugs, which are unstable at buccal pH may not administered by this system.

$\checkmark$ Macro molecule compound cannot be administered. 
$\checkmark$ After long time application, site saturation of buccal mucosa may occur, which may cause low permeability rate.

$\checkmark$ Only those drugs, which are absorbed by passive diffusion, can be $\quad$ administered by this route.

$\checkmark$ Only drugs with small dose requirements can be administered.

\subsubsection{Mucoadhesive Drug Delivery System in Oral Cavity ${ }^{(11)}$}

Drug delivery via the membranes of the oral cavity can be subdivided as follows:

Sublingual Delivery Drugs are delivered through mucosal membrane lining the floor of mouth into systemic circulation.

Buccal Delivery Drugs are delivered through mucosal membrane into systemic circulation by placing drug in between cheeks and gums.

Local Delivery Drugs are delivered into the oral cavity.

\subsubsection{Classification of Buccal Bio-Adhesive Dosage Form ${ }^{(12)}$}

\section{Buccal Bioadhesive Tablets}

Buccal bioadhesive tablets are dry dosage forms that are to be moistened after placing in contact with buccal mucosa. Double and multilayered tablets are already formulated using bioadhesive polymers and excipients. These tablets are solid dosage forms that ate prepared by the direct compression of powder and can be placed into contact with the oral mucosa and allowed to dissolve or adhere depending on the type of excipients incorporated into the dosage form. They can deliver drug multi- directionally into the oral cavity or to the mucosal surface.

\section{Buccal Bioadhesive Semisolid Dosage Forms}

Buccal bioadhesive semisolid dosage forms consist of finally powdered natural or synthetic polymers dispersed in a polyethylene or in aqueous solution example: Arabase.

\section{Buccal Bioadhesive Patches and Films}

Buccal bioadhesive patches consists of two ply laminates or multilayered thin film that are round or oval in shape, consisting of basically of bioadhesive polymeric layer and impermeable backing layer to provide unidirectional flow of drug across buccal mucosa. Buccal bioadhesive films are formulated by incorporating the drug in alcohol solution of bioadhesive polymer.

\section{Buccal Bioadhesive Powder Dosage Forms}

Buccal bioadhesive powder dosage forms are a mixture of bioadhesive polymers and the drug and are sprayed onto the buccal mucosa the reduction in diastolic B.P after the administration of buccal tablet and buccal film of Nifedipine.

\section{Buccal chewing gum}

Some commercial products of buccal chewing gum are available in the market like Caffeine chewing gum, Stay Alert, was developed recently for alleviation of sleepiness. It is absorbed at a significantly faster rate and its bioavailability was comparable to that in capsule formulation. Nicotine chewing gums (e.g., Nicorette and Nicotinell) have been marketed for smoking cessation. The permeability of nicotine across the buccal mucosa is faster than across the skin.

\section{Bioadhesive spray}

Buccoadhesive showers are increasing imperative over other measurements shapes as a result of adaptability, comfort, high surface zone and accessibility of medication in arrangement frame. The primary FDA-affirmed (1996) definition was produced by fentanyl Oralet ${ }^{\mathrm{T}}$ to exploit oral transmucosal ingestion for the effortless organization of a narcotic in a detailing worthy to kids. In 2002, the FDA affirmed Subutex (buprenorphine) for starting treatment of narcotic reliance (dependence on narcotic medications, including heroin and narcotic analgesics) and Suboxone (buprenorphine and naloxone) for proceeding with 
treatment of addicts. In 2005, Oral-lyn buccal splash was affirmed for business promoting and deals in Ecuador.

\subsection{Introduction of Disease}

- Diabetes ${ }^{(13)}$

Diabetes, frequently alluded to by specialists as diabetes mellitus, depicts a gathering of metabolic maladies in which the individual has high blood (glucose), either in light of the fact that insulin creation is insufficient, or on the grounds that the body's phones don't react legitimately to insulin, or both. Patients with high glucose will ordinarily encounter polyuria (visit pee), they will turn out to be progressively parched (polydipsia) and hungry (polyphagia).

\section{There are three kinds of diabetes:}

\section{1) Type 1 diabetes}

The body does not deliver insulin. A few people may allude to this sort as insulin-subordinate diabetes, adolescent diabetes, or early-beginning diabetes. Individuals as a rule create type 1 diabetes before their 40th year, frequently in early adulthood or high school years. Type 1 diabetes is no place close as regular as sort 2 diabetes. Around $10 \%$ of all diabetes cases are type 1.

\section{2) Type 2 diabetes}

The body does not deliver enough insulin for appropriate capacity, or the cells in the body don't respond to (insulin obstruction). Roughly $90 \%$ of all instances of diabetes worldwide are type 2 .

\section{3) Gestational diabetes}

This sort influences females amid pregnancy. A few ladies have abnormal amounts of glucose in their blood, and their bodies can't create enough insulin to transport the majority of the glucose into their cells, bringing about logically rising levels of glucose. Determination of gestational diabetes is made amid pregnancy.

\subsection{Introduction of Drug}

- Saxagliptin:-(14-20)

Table 1: Drug Information

\begin{tabular}{|l|l|}
\hline \multicolumn{2}{|l|}{ General Properties:- } \\
\hline Name & Saxagliptin \\
\hline Description & Saxagliptin is an orally anti-diabetic drug \\
\hline Appearance & $\begin{array}{l}\text { White to light yellow or light brown, non-hygroscopic, crystalline } \\
\text { powder. }\end{array}$ \\
\hline Structure & Anti diabetic Agent \\
\hline CAS number & $361442-04-8$ \\
\hline Category & \\
\hline
\end{tabular}


Mr. Vipul Pandit, et al, Journal of Pharmaceutical and Biological Science Archive

\begin{tabular}{|c|c|}
\hline Molecular Weight & $333.43 \mathrm{~g} / \mathrm{mol}$ \\
\hline Chemical Formula & $\mathrm{C}_{18} \mathrm{H}_{25} \mathrm{~N}_{3} \mathrm{O}_{2} \cdot \mathrm{H}_{2} \mathrm{O}$ \\
\hline IUPAC Name & $\begin{array}{l}(1 S, 3 S, 5 S)-2-[(2 S)-2 \text {-amino-2-(3-hydroxyadamantan-1-yl)acetyl]-2- } \\
\text { azabicyclo[3.1.0]hexane-3-carbonitrile }\end{array}$ \\
\hline Solubility & $\begin{array}{l}\text { Slightly soluble in ethyl acetate, and soluble in methanol, ethanol, } \\
\text { acetonitrile, isopropyl alcohol, acetone, and polyethylene glycol } 400 \\
\text { (PEG 400). It is sparingly soluble in water at } 24^{\circ} \mathrm{C} \pm 3^{\circ} \mathrm{C} \text {, }\end{array}$ \\
\hline Water Solubility & $2.26 \mathrm{mg} / \mathrm{ml}$ \\
\hline $\log P$ & 2.08 \\
\hline pKa & 7.90 \\
\hline Melting point $\left({ }^{\circ} \mathrm{C}\right)$ & $103-107^{\circ} \mathrm{C}$ \\
\hline Identification & FTIR, UV, HPLC \\
\hline BCS Class & III \\
\hline Dose & $2.5 / 5 \mathrm{mg}$ \\
\hline \multicolumn{2}{|c|}{ Pharmacokinetic Properties:- } \\
\hline Absorption & $\begin{array}{l}\text { Following a } 5 \mathrm{mg} \text { single oral dose of saxagliptin to healthy subjects, } \\
\text { the mean plasma AUC values for saxagliptin and its active metabolite } \\
\text { were } 78 \mathrm{ng} \cdot \mathrm{h} / \mathrm{ml} \text { and } 214 \mathrm{ng} . \mathrm{h} / \mathrm{ml} \text {, respectively. }\end{array}$ \\
\hline Bioavailability & $50 \%$ \\
\hline Protein binding & $<10 \%$ \\
\hline Metabolism & Hepatic metabolism \\
\hline Half life & 2.5 hours \\
\hline Excretion & Saxagliptin is eliminated by both renal and hepatic pathways. \\
\hline \multicolumn{2}{|c|}{ Pharmacological Properties:- } \\
\hline Indication & Treatment of type 2 diabetes mellitus \\
\hline Mechanism of action & Saxagliptin is a dipeptidyl peptidase-4 (DPP-4) inhibitor \\
\hline
\end{tabular}


Mr. Vipul Pandit, et al, Journal of Pharmaceutical and Biological Science Archive

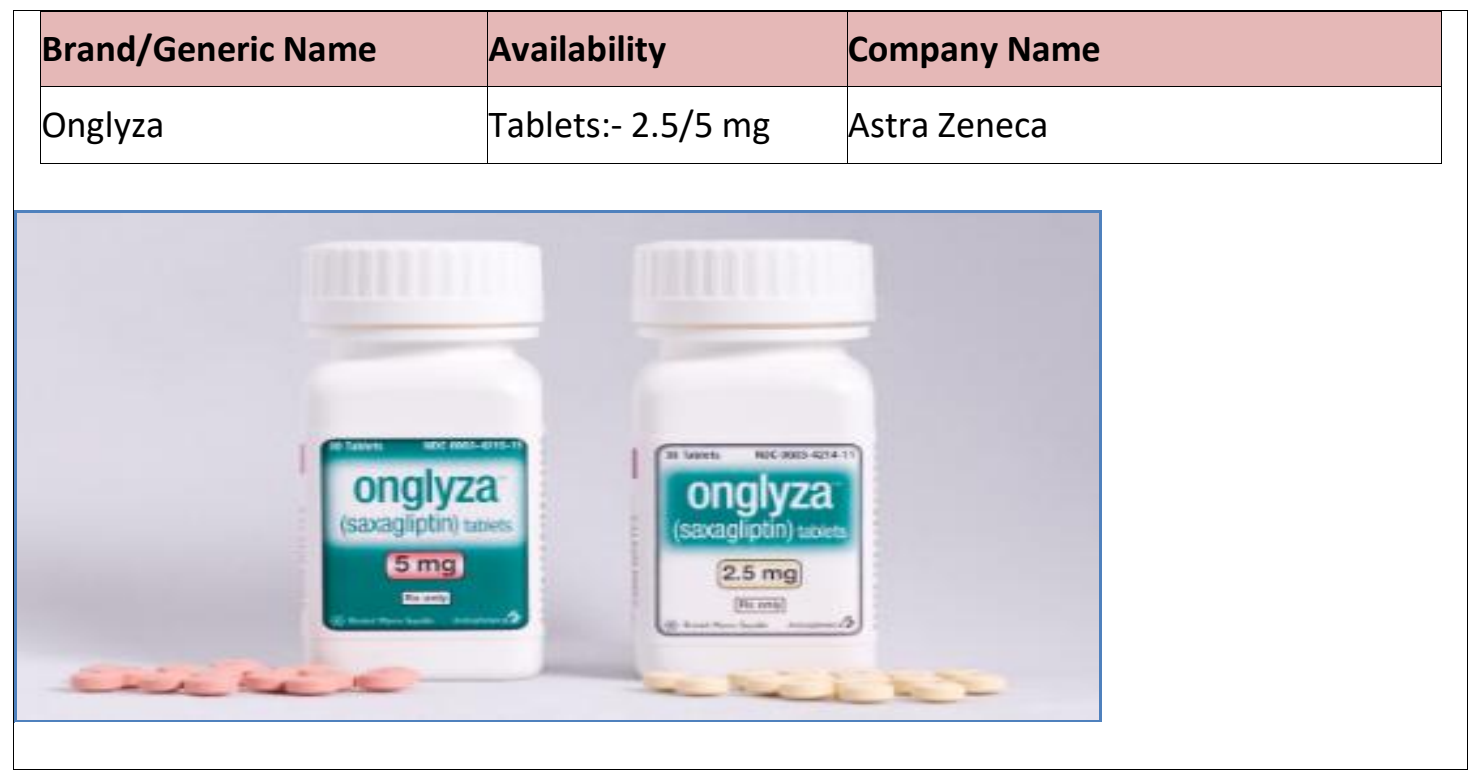

\subsection{Introduction of Excipients}

- PEG 400 (Polyethylene Glycol)

\begin{tabular}{|c|c|c|}
\hline Nonproprietary Names & : & $\begin{array}{l}\text { BP: Macrogols } \\
\text { JP: Macrogol } 400 \\
\text { Macrogol } 1500 \\
\text { Macrogol } 4000 \\
\text { Macrogol } 6000 \\
\text { Macrogol } 20000 \\
\text { Ph. Eur: Macrogols } \\
\text { USP-NF: Polyethylene Glycol }\end{array}$ \\
\hline Synonyms & : & $\begin{array}{l}\text { Carbowax; Carbowax Sentry; Lipoxol; Lutrol E; macrogola; } \\
\text { PEG; Pluriol E; polyoxyethylene glycol. }\end{array}$ \\
\hline Chemical Name & : & a-Hydro-o-hydroxypoly(oxy-1,2-ethanediyl) \\
\hline CAS Registry Number & & 25322-68-3] \\
\hline Structural Formula & : & $\mathrm{HO}-\left.\right|_{\mathrm{H}} ^{\mathrm{H}}-\left(\mathrm{CH}_{2}-\mathrm{O}-\mathrm{CH}_{2}\right)_{m}-\left.\right|_{\mathrm{H}} ^{\mathrm{C}}-\mathrm{OH}$ \\
\hline Functional Category & : & Plasticizer; \\
\hline $\begin{array}{l}\text { Applications } \\
\text { Pharmaceutical } \\
\text { Formulation } \\
\text { Technology }\end{array}$ & & $\begin{array}{l}\text { Polyethylene glycols (PEGs) are widely used in a variety of } \\
\text { pharmaceutical formulations, including parenteral, topical, } \\
\text { ophthalmic, oral, and rectal preparations. Polyethylene } \\
\text { glycol has been used experimentally in biodegradable } \\
\text { polymeric matrices used in controlled-release systems. }\end{array}$ \\
\hline
\end{tabular}

\section{- Sodium Alginate}


Mr. Vipul Pandit, et al, Journal of Pharmaceutical and Biological Science Archive

\begin{tabular}{|c|c|c|}
\hline Nonproprietary Names & : & $\begin{array}{l}\text { BP : Sodium alginate } \\
\text { PhEur : Natrii alginas } \\
\text { USPNF : Sodium alginate }\end{array}$ \\
\hline Synonyms & $:$ & $\begin{array}{l}\text { E400, Kelacid, L-gulo-D-mannoglycuronan, Polymanuronic } \\
\text { acid, Protacid, Satialgin }\end{array}$ \\
\hline Empirical Formula & : & $\left(\mathrm{C}_{6} \mathrm{H}_{7} \mathrm{O}_{8} \mathrm{Na}\right) \mathrm{n}$ \\
\hline Structural Formula & : & 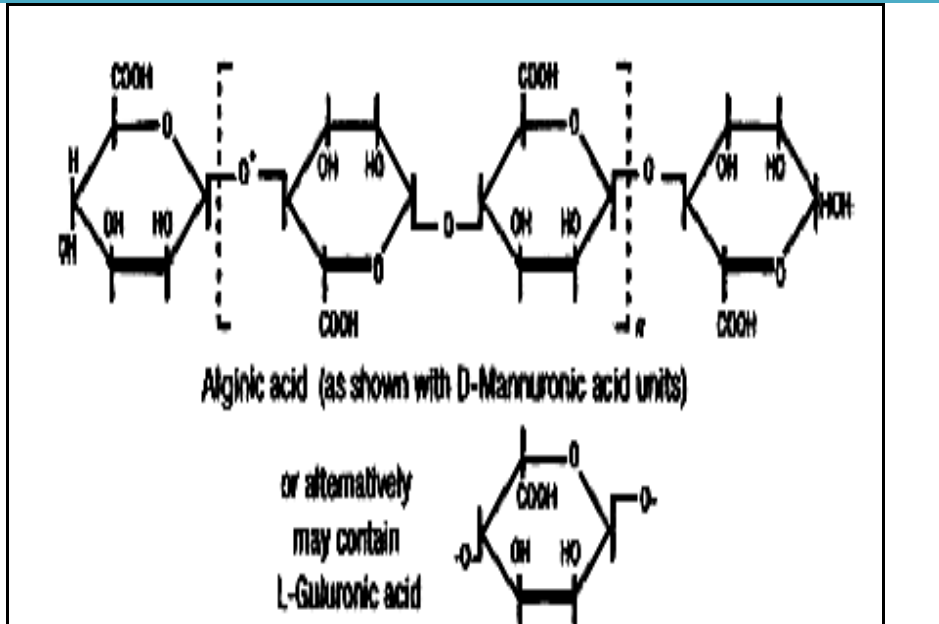 \\
\hline Functional Category & : & $\begin{array}{l}\text { Suspending agent (1-3\%), stabilizing agent (1-3 \%), } \\
\text { viscosity-increasing agent (5-10\%), disintegrating agent (5- } \\
10 \%) \text { and tablet binder. }\end{array}$ \\
\hline
\end{tabular}

- Chitosan

\begin{tabular}{|lll|}
\hline Nonproprietary Names & : & $\begin{array}{l}\text { BP: Chitosan Hydrochloride } \\
\text { PhEur: Chitosan Hydrochloride }\end{array}$ \\
\hline Synonyms & $: \begin{array}{l}\text { 2-Amino-2-deoxy-(1,4)-b-D-glucopyranan; chitosani } \\
\text { hydrochloridum; deacetylated chitin; deacetylchitin; b-1,4- } \\
\text { poly-D-glucosamine; poly-D-glucosamine; poly-(1,4-b-D- } \\
\text { glucopyranosamine) }\end{array}$ \\
\hline $\begin{array}{l}\text { Chemical Name and CAS } \\
\text { Registry Number }\end{array}$ & $: \begin{array}{l}\text { Poly-b-(1,4)-2-Amino-2-deoxy-D-glucose } \\
{[9012-76-4]}\end{array}$ \\
\hline Empirical Formula & $:$ & $\begin{array}{l}\text { Partial deacetylation of chitin results in the production of } \\
\text { chitosan, which is a polysaccharide }\end{array}$ \\
\hline
\end{tabular}


Mr. Vipul Pandit, et al, Journal of Pharmaceutical and Biological Science Archive

\begin{tabular}{|lll|}
\hline Structural Formula & $:$ \\
\hline Functional Category & $\begin{array}{l}\text { Coating agent; disintegrant; film-forming agent; } \\
\text { mucoadhesive; tablet binder; viscosity increasing agent. }\end{array}$ \\
\hline $\begin{array}{l}\text { Applications } \\
\text { Pharmaceutical } \\
\text { or Technology }\end{array}$ & Formulation & $\begin{array}{l}\text { Chitosan is used in cosmetics and is under investigation for } \\
\text { use in a number of pharmaceutical formulations. The } \\
\text { suitability and } \\
\text { performance of chitosan as a component of pharmaceutical } \\
\text { formulations for drug delivery applications has been } \\
\text { investigated in numerous studies. }\end{array}$ \\
\hline
\end{tabular}

- Acesulfame Potassium

\begin{tabular}{|c|c|}
\hline Nonproprietary Names & $\begin{array}{l}\text { BP: Acesulfame Potassium } \\
\text { PhEur: Acesulfame Potassium } \\
\text { USP-NF: Acesulfame Potassium }\end{array}$ \\
\hline Synonyms & $\begin{array}{l}\text { Acesulfame K; ace K; acesulfamum kalicum; E950; 6-methyl-3, 4- } \\
\text { dihydro-1,2,3-oxathiazin-4(3H)-one-2,2-dioxide potassium salt; } \\
\text { potassium 6-methyl-2,2-dioxo-oxathiazin-4-olate; Sunett; Sweet One. }\end{array}$ \\
\hline CAS Number & 55589-62-3 \\
\hline Functional Category & Sweetening agent. \\
\hline Structure & $\|_{s}^{0}=0$ \\
\hline Appearance & $\begin{array}{l}\text { Acesulfame potassium occurs as a colorless to white-colored, } \\
\text { odorless, crystalline powder with an intensely sweet taste. }\end{array}$ \\
\hline Application & $\begin{array}{l}\text { Acesulfame potassium is used as an intense sweetening agent in cosmetics, } \\
\text { foods, beverage products, table-top sweeteners, vitamin and } \\
\text { pharmaceutical preparations, including powder mixes, tablets, and liquid } \\
\text { products. It is widely used as a sugar substitute in compounded formulations }\end{array}$ \\
\hline
\end{tabular}




\section{LITERATURE REVIEW}

\subsection{Review of Literature on Drug Delivery System}

Puja $S$ et al ${ }^{(21)}$ worked on buccal patches of aceclofenac for gingivitis. For patch preparation different polymer such as like HPMC 5cps, carbopol 934p, Eudragit RL 100 in various combinations. The buccal patches were prepared by solvent casting method. After all studies, formulation F7 containing HPMC $5 \mathrm{cps}$ and Eudragit RL 100 in the ratio (400 mg: $200 \mathrm{mg}$ ) was selected as optimized formulation and its mucoadhesive strength and exhibited optimum drug release.

Ashutosh $\mathbf{R}$ et al ${ }^{(22)}$ prepared mucoadhesive buccal patches of hydrochlorothiazide (HCZ) and atenolol (ATN) by solvent casting technique usingvarious concentrations of sodium alginate, hydroxyl propyl methyl cellulose, carbopol 934P and sodium carboxy methyl cellulose polymer and polyvinyl alcohol as a backing layer. The formulated patches were evaluated for their physicochemical parameters like thickness, weight variation, surface $\mathrm{pH}$, content uniformity, folding endurance, swelling percentage studies and tensile strength, in vitro and ex vivo drug permeation. Among the patches, FC (Carbopol 934 and HPMC) patches were considered satisfactory for maintaining the in vitro residence in the oral cavity for almost $8 \mathrm{~h}$.

Ashutosh $\mathbf{R}$ et al ${ }^{(23)}$ developed mucoadhesive buccal film as a promising dosage form, which has prominent advantages because of drug delivery through buccal mucosa. New formulation of buccal films containing rizatriptan benzoate (RB) was prepared by solvent casting method using various concentrations of hydroxypropyl methylcellulose (HPMC K4M), polyvinyl alcohol (PVA), polyethylene oxide (PEO), glycerol, stevia, and goat buccal mucosa used as a model membrane. In this work, the effect of polymers and plasticizer concentrations on drug release profile, disintegration and dissolution time, mechanical properties, and mucoadhesive characteristics of films was studied.

Anilkumar $\mathbf{J}$ et al ${ }^{\text {(24) }}$ formulated and developed mucoadhesive buccal film of nebivolol by using solvent casting method. Prepared mucoadhesive buccal films using HPMC E15 and PVP as mucoadhesive polymers. Among the two polymers used HPMC E15 showed an increased in-vitro residence time due to high mucoadhesive property.

Anilkumar $\mathbf{J}$ et al ${ }^{(25)}$ prepared bilayered mucoadhesive buccal film containing a combination of ornidazole (OD) and dexamethasone sodium phosphate (DEX) was using solvent casting to treat oral ulcers. Films were systematically evaluated in vitro to obtain the optimum formulation. The therapeutic effects of these films were investigated in the rabbit oral ulcer model and the in vivo release of OD and DEX in the human oral cavity was also evaluated. The backing layer contained ethyl cellulose and an optimal mucoadhesive layer containing both OD and DEX was produced.

Pooja S et al ${ }^{(26)}$ Formulated and Evaluated of mucoadhesive Buccal Patch of Timolol Maleate as model drug and using either ionic polymers (SCMC) or non-ionic polymers (carbopol, HPMC). The fabricated patches were prepared by solvent casting method. The mean thicknesses of the buccal patch formulations were $0.34-0.43 \mathrm{~mm}$. Moisture uptake of transdermal patches were found to be 2.94-4.13.which prevents the patches from microbial growth and bulkiness. As amount of PVP increased in every polymer blend, tensile strength and elongation at break were increased. Bioadhesive strength of buccal patches in following order SCMC >Carbopol>HPMC.

Ali R et al ${ }^{(27)}$ developed buccal tablets of piroxicam by using hydroxypropyl methylcellulose and chitosan as mucoadhesive agents. Tablets were prepared with direct compression method and evaluated for physical properties. In vitro dissolution studies showed that the release rate of PX from the formulations affected by type and ratio of polymers. The release mechanism of PX from buccal tablets follows diffusive mechanism with first order and Higuchi release kinetics. In vivo studies of optimum buccal tablet formulation carried out on human healthy volunteers showed that the relative bioavailability of PX was $67.52 \pm 21.47 \%$. These results demonstrate that buccal tablet formulation of $\mathrm{PX}$ seems to be an alternative drug delivery for patients especially suffering from $\mathrm{Gl}$ disturbances.

Rohan $\mathbf{M}$ et al ${ }^{(28)}$ focused on various aspects of buccal films, factors affecting mucoadhesion and its evaluating parameters. Different theories involved in mucoadhesion process and along with the polymers that are involved in developing different categories of films have been focused. Factors influencing the 
polymers involved flexibility, molecular weight, charge, etc., are also considered in this review. Most commonly used polymers in the development of mucoadhesive films are lectins, starch, pectins, and cellulose derivatives, etc. Several agents such as penetration enhancers and mucoadhesive agents are employed to develop an ideal film. These dosage forms are formulated using two processes, namely film casting method and hot-melt extrusion method.

Balakrishna T et al ${ }^{(29)}$ developed fast dissolving buccal films of which is an effective and well-tolerated treatment option in the management of acid-related disorders. Lansoprazole fast dissolving buccal films are a new, patient-friendly, and more convenient formulation of which can be taken with or without water. polyvinyl alcohol and polyvinylpyrrolidone were used as film-forming agents, and polyethylene glycol 400 is taken as plasticizer. Solvent casting method was used for the preparation of fast dissolving buccal films.

Rajesh P et al ${ }^{\left({ }^{(30)}\right.}$ reported on salbutamol sulphate buccal delivery. The patches of Poly vinyl alcohol (PVA), Hydroxy propyl methyl cellulose (HPMC) and Chitosan in presence of Poly vinyl pyrrolidone (PVP) and Carbopol already reported earlier. The salbutamol patches composed of different compositions of Eudragit RL 100, Ethyl cellulose (EC) and HPMC are reported.

\subsection{Review of Literature on Drug}

Talat $\mathbf{F}$ et al ${ }^{(31)}$ formulated mucoadhesive microspheres of saxagliptin, to achieve reduced dosing frequency, increased bioavailability, increased patient compliance and decreased drug related adverse effects. This objective is achieved by formulating the mucoadhesive microspheres of the drug using orifice ionotropic gelation technique. Sodium alginate is used as a polymer while calcium chloride as counterion and HPMC K4M as mucoadhesive polymer.

Iswariya $\mathbf{V}$ et al ${ }^{\left({ }^{(32)}\right.}$ focused on the development and evaluation of oro dispersive tablets of saxagliptin in the treatment of diabetes. The formulae was developed using various individual concentrations of super disintegrating agents. The compatibility of Drug and excipients was evaluated using FTIR studies. The tablets were prepared and Pre- and Post-compression parameters, wetting time and in-vitro dissolution and stability studies were evaluated. The FT-IR spectra's confirms the absence of chemical interaction between drug and excipients. All the Pre- and post-compression parameters were found to be in limits. From the results of dissolution testing, it was found that the formulation F6 found to be best of all the formulations.

Shubhangi $\mathbf{C}$ et al ${ }^{(33)}$ developed and demonstrated an integrated multivariate approach to develop and quantify the constituent concentrations of saxagliptin drug in its pure and formulated forms.

Margret $\mathbf{C}$ et al ${ }^{(34)}$ developed Saxagliptin immediate release and Metformin hydrochloride sustained release tablets formulated employing Hydroxy Propyl Methyl Cellulose polymer and carmellose sodium polymer, the drug release behavior of the tablets was investigated.

Kalaichelvi R et al ${ }^{(35)}$ developed simple, sensitive and cost effective UV spectrophotometric method was for the estimation of saxagliptin in bulk and pharmaceutical formulations. 
Mr. Vipul Pandit, et al, Journal of Pharmaceutical and Biological Science Archive

\subsection{Summary of PSAR Report}

\begin{tabular}{|l|l|l|}
\hline Sr. No. & $\begin{array}{l}\text { Patent Application } \\
\text { number }\end{array}$ & Title of Patent \\
\hline & $547 / \mathrm{MUM} / 2015$ & $\begin{array}{l}\text { Extended Release Combination Compositions of Saxagliptin } \\
\text { and Methyldopa }\end{array}$ \\
\hline & $3582 / \mathrm{MUM} / 2012$ & $\begin{array}{l}\text { Stable Pharmaceutical Compositions of Saxagliptin or Salts } \\
\text { Thereof }\end{array}$ \\
\hline & $2646 / \mathrm{MUM} / 2012$ & Stable Pharmaceutical Composition of Saxagliptin \\
\hline & $700 / \mathrm{MUM} / 2012$ & Pharmaceutical Compositions of Saxagliptin \\
\hline & US20110033541A1 & Sublingual and buccal film composition \\
\hline
\end{tabular}

- Looking at above 05 patents, your Dissertation project is novel up to what extent?

Novelty grade: 50 to $90 \%$

- RATIONAL OF PATENT

Above five patents describes Formulation of Saxagliptin in different dosage form. No any work done on buccal drug delivery system of Saxagliptin. Hence, the selected title is novel. Buccal films of saxagliptin by pass the hepatic first pass effect and improve bioavailability of drug. 
Mr. Vipul Pandit, et al, Journal of Pharmaceutical and Biological Science Archive

\section{AIM \& OBJECTIVES}

\subsection{Aim of Work}

"Formulation and Evaluation of Buccal films of Saxagliptin"

\subsection{Rationale}

$\checkmark$ Saxagliptin is an anti-diabetic drug of the new dipeptidyl peptidase-4 (DPP-4) inhibitor class of drugs.

$\checkmark \quad$ It is conventionally available as tablet dosage form in two different strengths, $2.5 / 5 \mathrm{mg}$.

$\checkmark \quad$ Its molecular weight is $315.41 \mathrm{~g} / \mathrm{mol}$.

$\checkmark$ Biological half life is 2.5 hour. Due to short half life it's require to take 3-4 times in a day.

$\checkmark \quad$ Log $P$ value is $\mathbf{0 . 8 8}$ and pKa value is $\mathbf{1 4 . 7 4}$.

$\checkmark$ Bioavailability is less (50\%) due to hepatic first pass effect.

$\checkmark \quad$ It's a BCS class III drug with high water solubility $2.26 \mathrm{mg} / \mathrm{ml}$.

$\checkmark$ The short half-life, Low molecular weight, low dose and good water solubility makes Saxagliptin good candidate for buccal films (Sustained release) of also favors development of a sustained release formulation.

$\checkmark$ Hence, the buccal films of saxagliptin to be developed for sustained action of drug, reduce dosing frequency, bypass the hepatic first pass effect and improve bioavailability.

\subsection{Objectives of Work}

$\checkmark$ To carry out pre-formulation studies for possible drug and excipient interactions. (Drug: Excipient Compatibility study)

$\checkmark$ To formulate buccal films of Saxagliptin.

$\checkmark$ To optimize the amount of polymer on drug release.

$\checkmark$ To optimize the amount of plastsizer in buccal films.

$\checkmark$ To achieve more than $80 \%$ drug release in 8 hour.

To carry out accelerated stability studies on the most satisfactory formulation as per ICH guideline. 
4. MATERIALS AND EQUIPMENTS

\subsection{List of Materials}

Table 2: List of materials

\begin{tabular}{|l|l|l|l|}
\hline Sr. No. & Material & Function & Sources of Material \\
\hline 1. & Saxagliptin & API & Alembic, Baroda. \\
\hline 2. & Acesulfame Potassium & Sweetener & Balaji Chemicals, Ahmedabad \\
\hline 3. & PEG 400 & Plasticizer & Balaji Chemicals, Ahmedabad \\
\hline 4 & $\begin{array}{l}\text { Chitosan, } \\
\text { Sodium Alginate }\end{array}$ & Film forming Polymers & Balaji Chemicals, Ahmedabad \\
\hline
\end{tabular}

\subsection{List of Equipments}

Table 3: List of equipments

\begin{tabular}{|l|l|l|}
\hline Sr. No. & Equipments & Manufacturers \\
\hline 1. & Digital weighing balance & $\begin{array}{l}\text { Reptech weighing balance Itd., } \\
\text { Ahmadabad }\end{array}$ \\
\hline 2. & Dissolution apparatus & Electro lab Itd, Mumbai \\
\hline 3. & $\begin{array}{l}\text { U. V. Visible } \\
\text { spectrophotometer }\end{array}$ & Shimadzu-1601, Kroyoto, Japan. \\
\hline 4. & FTIR & FTIR8400S, Shimadzu, Kroyoto, Japan. \\
\hline 5. & Magnetic stirrer. & Janki Impex Pvt. Ltd, Ahmedabad \\
\hline 6. & pH Meter & Janki Impex Pvt. Ltd, Ahmedabad \\
\hline
\end{tabular}

\section{EXPERIMENTAL WORK}

Experimental Work is basically divided in three major parts;

1. Preformulation Study

2. Development of Buccal films

3. Evaluation of Buccal films

\subsection{PRE FORMULATION STUDIES}

\subsubsection{CHARACTERIZATION OF DRUG (SAXAGLIPTIN)}

\subsubsection{Organoleptic Characteristics:}

Colour and Odor of Drug were characterized and recorded using descriptive terminology.

\subsubsection{Flow Properties}

\section{1) Bulk density and tapped density}

An accurately weighed quantity of the API (W), was carefully poured into the graduated cylinder and the volume (Vo) was measured. Then the graduated cylinder was set for 100 taps and after that the volume (Vf) was measured which was tapped volume. The bulk density and tapped density were calculated by using the following formulas. 
Bulk density $=\mathrm{W} / \mathrm{V} 0$, Tapped density $=\mathrm{W} / \mathrm{Vf}$

2) Compressibility index (Cl) / Carr's index

It was obtained from bulk and tapped densities. It was calculated by using the following formula.

\% Carr's index = (T.D. - B.D. $\div$ T.D.) $\times 100$

3) Hausner's ratio

Hausner's ratio is a number that is correlated to the flow ability of a powder. It is measured by ratio of tapped density to bulk density.

Hausner's ratio $=$ (Tapped density $\div$ Bulk Density $)$

\section{4) Angle of repose}

Angle of repose of API powder was determined by the funnel method. Accurately weight powder blend was taken in the funnel. Height of the funnel was adjusted in such a way the tip of the funnel just touched the apex of the powder blend. Powder blend was allowed to flow through the funnel freely on to the surface. Diameter of the powder cone was measured and angle of repose was calculated using the following equation.

$\operatorname{Tan} \theta=h / r$

\subsubsection{DRUG EXCIPIENTS COMPATIBILITY STUDY}

\subsubsection{FTIR Study}

The Fourier transform infrared spectrum of moisture free powdered sample of Drug and final formulation was recorded on IR spectrophotometer by potassium bromide $(\mathrm{KBr})$ pellet method. The range of spectra was found to be 400 to $4000 \mathrm{~cm}^{-1}$. The characteristics peaks of different functional group were compared with reported standard peak.

\subsection{DETERMINATION OF $\lambda \max$ AND DEVELOPMENT OF CALIBRATION CURVE OF SAXAGLIPTIN}

Stock Solution: Saxagliptin in 6.8 Phosphate buffer solutions. $(100 \mu \mathrm{g} / \mathrm{ml})$.

Scanning: From the stock solution, a suitable concentration $(10 \mu \mathrm{g} / \mathrm{ml})$ was prepared with 6.8 Phosphate buffer solutions and UV scan was taken between the wavelengths of 200-400 nm and determining its $\lambda$ max.

Standard Plot: From the stock solution 2 to $12 \mu \mathrm{g} / \mathrm{ml}$ solutions of Saxagliptin were prepared in 6.8 Phosphate buffer solutions. The absorbance was measured at $208 \mathrm{~nm}$ and a graph of concentration versus absorbance was plotted.

\subsection{DOSE CALCULATION}

\subsubsection{FOR SUSTAINED RELEASE FORMULATION}

For sustained release drug up to 8 hours, the total dose of drug required was calculated based on the fact that the conventional dose was $2.5 \mathrm{mg}$. the total dose was calculated using the following equation,

$D_{t}=$ Dose $\left(1+0.693 \times t / t_{1 / 2}\right)$

Where,

$D_{\mathrm{t}}=$ Total dose,

Dose=immediate release dose/ Loading Dose: $-2.5 \mathrm{mg}$

$\mathrm{t}=$ Total time period for which sustained release is required: $-8 \mathrm{hr}$.

$\mathrm{t}_{1 / 2}=$ Half life of drug: $-2.5 \mathrm{hr}$.

$\mathrm{D}_{\mathrm{t}}=2.5(1+0.693 \times 8 / 2.5)$

$=8.0 \mathrm{mg}$ of $d r u g$ require for $8 \mathrm{hr}$ sustained release effect. 


\subsubsection{THEORETICAL DRUG RELEASE PROFILE:}

$2.5 \mathrm{mg}$ of loading dose release in first hour and remaining $5.5 \mathrm{mg}$ of drug release in 7 hours equally. Hence the target release profile should be as per below;

\begin{tabular}{|lll|}
\hline Hour & mg of Drug Release & \% Drug release \\
\hline $\mathbf{1}$ & 2.5 & 31.3 \\
\hline $\mathbf{2}$ & 3.29 & 41.1 \\
\hline $\mathbf{3}$ & 4.07 & 50.9 \\
\hline $\mathbf{4}$ & 4.86 & 60.7 \\
\hline $\mathbf{5}$ & 5.64 & 70.5 \\
\hline $\mathbf{6}$ & 6.43 & 80.4 \\
\hline $\mathbf{7}$ & 7.21 & 90.2 \\
\hline $\mathbf{8}$ & 8.00 & 100 \\
\hline
\end{tabular}

\subsubsection{DOSE CALCULATION OF SAXAGLIPTIN FOR FILM PRAPARATION}

$>$ Diameter of the Petridish $=8.0 \mathrm{~cm}$

$>$ Radius $=$ Diameter $/ 2=8.0 / 2=4.0 \mathrm{~cm}$.

$>$ Area of Petridish $A=\pi r^{2}=3.14 \times 4.00 \times 4.00=50.24 \mathrm{~cm}^{2}$

$>$ Now, Dose is $8.0 \mathrm{mg}$ and cut the pieces in $2 \mathrm{~cm} \times 2 \mathrm{~cm}=4 \mathrm{~cm}^{2}$

$4 \mathrm{~cm}^{2}$ contain $8.0 \mathrm{mg}$ drug,

So, $50.24 \mathrm{~cm}^{2}$ contain (?)

Amount of Drug $=100.48 \mathrm{mg} \sim 100.0 \mathrm{mg}$ of Saxagliptin require

5.4 PREPARATION OF SAXAGLIPTIN BUCCAL FILMS: -

\section{Solvent Casting Method:}

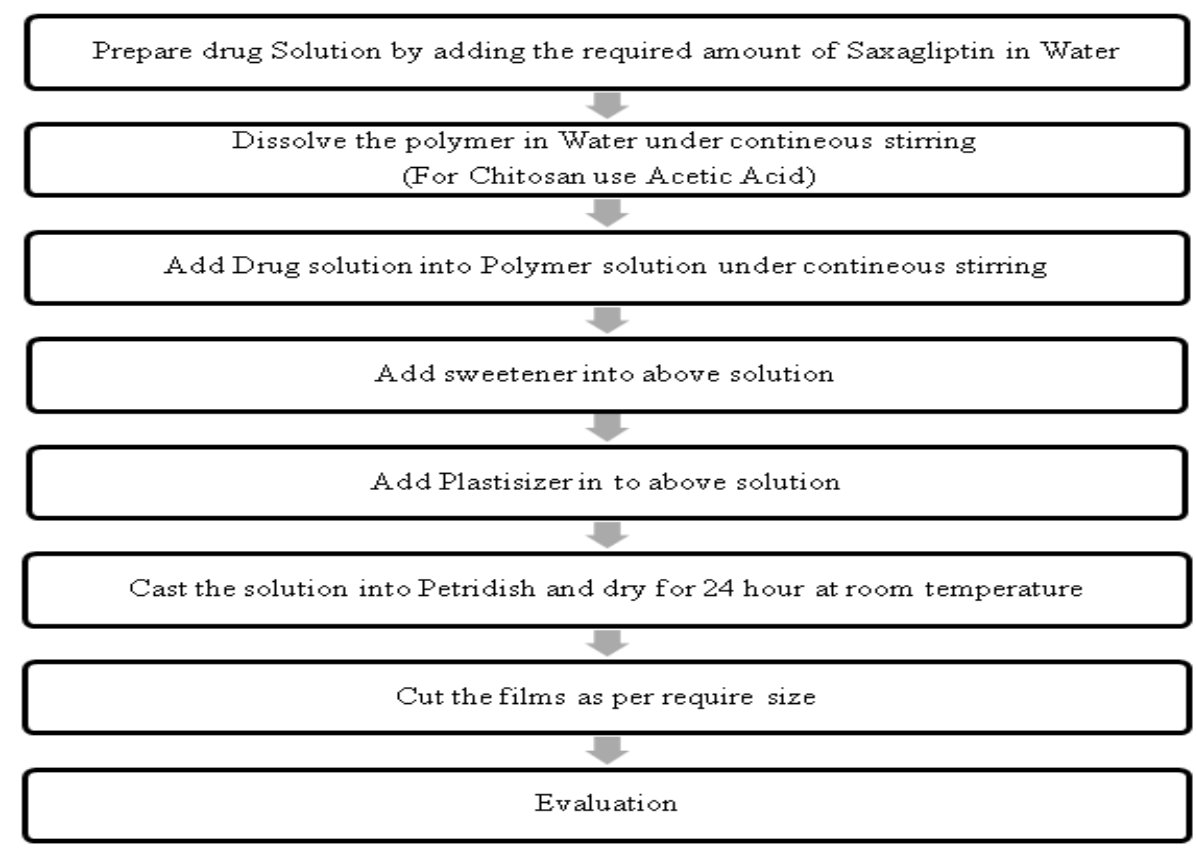


5.5 FORMULATION TABLE OF SAXAGLIPTIN BUCCAL FILMS: -

Table 4 Formulation table of Saxagliptin Buccal films trial batches

\begin{tabular}{|c|c|c|c|c|}
\hline Ingredients (mg/film) & F1 & F2 & F3 & F4 \\
\hline Saxagliptin & 8.0 & 8.0 & 8.0 & $\mathbf{8 . 0}$ \\
\hline Sodium Alginate & 1000 & 900 & 800 & $\mathbf{7 5 0}$ \\
\hline Chitosan & - & 100 & 200 & $\mathbf{2 5 0}$ \\
\hline PEG 400 (ml) & 10 & 10 & 10 & $\mathbf{1 0}$ \\
\hline Acesulfame Potassium & 5 & 5 & 5 & $\mathbf{5}$ \\
\hline Water (ml) & Q.S & Q.S & Q.S & Q.S \\
\hline
\end{tabular}

$\rightarrow$ The trial batches of buccal films were started with a single polymer Sodium alginate by taking $1000 \mathrm{mg}$ amount per film.

$\rightarrow$ To achieve desired drug release profile the amount of sodium alginate changes and Chitosan was incorporated in to it.

$\rightarrow$ PEG 400 used as a plastsizer as it was mostly used in films formulations.

$\rightarrow$ Acesulfame Potassium used as a sweetener in formulation.

\subsection{EVALUATION OF SAXAGLIPTIN BUCCAL FILMS ${ }^{25-29}$}

\subsubsection{Weight Variation:}

The weight of each of three randomly selected films from every formulation batch was determined by using an electronic balance.

\subsubsection{Thickness:}

The thickness of ten randomly selected films from every formulation batch was determined using a Vernier caliper.

\subsubsection{Folding Endurance:}

Folding endurance was determined by repeatedly folding the film at the same place till it broke or folded up to 300 times.

\subsubsection{Surface $\mathrm{pH}$ :}

The surface $\mathrm{pH}$ of the prepared buccal films was determined to evaluate the possible irritation effects on the mucosa. The films were left to swell in $5 \mathrm{ml}$ of distilled water $(\mathrm{pH} \mathrm{6.8)} \mathrm{in} \mathrm{small} \mathrm{beakers,} \mathrm{and} \mathrm{the} \mathrm{pH} \mathrm{was}$ measured by placing the electrode in contact with the microenvironment of the swollen films. The average $\mathrm{pH}$ of three determinations was reported.

\subsubsection{Drug Content Uniformity:}

The patch of known weight (dimension $2 \times 2 \mathrm{~cm}^{2}$ ) was extracted with $100 \mathrm{ml}$ of 6.8 phosphate buffer by shaking. The solution was suitably diluted with phosphate buffer and the absorbance was measured in UVspectrophotometer at $208 \mathrm{~nm}$ against the same phosphate buffer.

\subsubsection{Percent Swelling Index:}

The polymeric films cut into $2 \times 2 \mathrm{~cm}$ were weighed accurately and kept immersed in $50 \mathrm{ml}$ of water. The patches were taken out carefully at 2, 4, 6, and $8 \mathrm{hr}$. intervals blotted with filter paper to remove the water present on their surface and weighed accurately, the percent swelling is calculated using formula; 


$$
\text { Swelling }(\%)=\frac{\text { (wet weight }- \text { dry weight })}{\text { dry weight }} \times 100
$$

\subsubsection{Mechanical Characterization of the Films:}

Mechanical parameters, tensile strength and elongation at break were calculated from the load time profiles of the films using tensile tester. Upper and lower grips of the sample with a gauge length of $5 \times 1$ $\mathrm{cm}$, were attached to the crosshead and the base plate respectively in such a way that the former was located exactly $5 \mathrm{~cm}$ above the latter. The crosshead was moved upwards at a speed of $1 \mathrm{~cm} / \mathrm{s}$. The force and elongation were measured when the film broke. Results were reported as the mean ( $\pm \mathrm{SD}$ ) of three replicates.

Tensile strength $\left(\mathrm{kg} \mathrm{mm}^{-2}\right)=\frac{\text { Force at break }(\mathrm{kg})}{\text { Initial cross - sectional area of sample }\left(\mathrm{mm}^{2}\right)}$
Elongation at break $\left(\% \mathrm{~mm}^{-2}\right)=\frac{\text { Increase in length }(\mathrm{mm}) \times 100}{\text { Original length }(\mathrm{mm}) \times \text { cross sectional area }\left(\mathrm{mm}^{2}\right)}$

\subsubsection{In-vitro drug release:}

The dissolution study was carried out using USP Type-2 rotating paddle dissolution test apparatus. Therefore, to provide sink condition, $100 \mathrm{ml}$ of 6.8 phosphate buffer was taken as the dissolution medium in a $250 \mathrm{ml}$ glass beaker maintained at $37 \pm 0.5^{\circ} \mathrm{C}$ which was stirred at $50 \mathrm{rpm} .2 \mathrm{~cm}$ in diameter film was fixed by using acyanoacrylate adhesive on the glass disk. At the bottom of the dissolution vessel the disk was kept so that the film remains on the upper side of the disk. At pre-determined time intervals $5 \mathrm{ml}$ samples withdrawn and replaced with same volume of dissolution medium. These samples have been filtered using $0.45 \mu \mathrm{m}$ filter and diluted suitably with 6.8 phosphate buffer and assayed spectrophotometrically $208 \mathrm{~nm}$ respectively.

\subsubsection{Release Kinetic Study:}

The drug release mechanism from the buccal films was analyzed by ruling the best fit of the release data to zero order, first order, Hixon crowell, Higuchi and Korsmeyer - Peppa's plots.' For each model the release rate constants ' $k$ ' and ' $n$ ' were estimated by linear regression analyses.

\subsubsection{Ex-vivo permeation:}

Franz-diffusion cell was used for the drug permeation study of films with fresh buccal mucosa of sheep at $37 \pm 0.5^{\circ} \mathrm{C}$. The tissue preparation was similar to that explained before. Freshly obtained buccal mucosa was placed for connecting the donor and receptor compartments, thus the mucosa of smooth surface faced the donor compartment. After the animal mucosa was attached on one side of an open-ended tube, and it was served as a donor compartment. The film was located in such a way that it must be stuck on surface of mucous membrane. The diffusion cell was maintained at $37 \pm 2{ }^{\circ} \mathrm{C}$ and the receptor compartment was stimulated at a rate of $100 \mathrm{rpm}$. At pre-determined time intervals $1 \mathrm{ml}$ sample was taken using a butterfly canula and syringe. Sample filtered through $0.45 \mu \mathrm{m}$ filter and diluted suitably for analyzing drug content using UV spectrophotometer at $208 \mathrm{~nm}$.

\subsubsection{Buccoadhesive strength: (Mucoadhesive Strength)}

The force required to detach the bioadhesive films from the mucosal surface was applied as a measure of the bioadhesive performance. The instrument is broadly composed of a modified two arm physical balance in which the right pan had been replaced by a formulation holding glass plate $(10 \times 5 \mathrm{~cm})$ and counter balanced by a water collecting pan suspended to the left arm. The pan received a siphon tube from a $10 \mathrm{~L}$ 
bottle, which was kept at a high place in such a way that water head in the bottle always remains above the water collecting pan. The siphon tube bears a flow regulating device. Nylon thread was used to suspend both the glass plate and the pan. An acrylate tissue mounting stage $(1.8 \times 1.8 \times 8 \mathrm{~cm})$ was attached to the center of a glass beaker ( $16 \mathrm{~cm}$ diameter and $18 \mathrm{~cm}$ height). Glass beaker was filled with phosphate buffer ( $\mathrm{pH}$ 6.8) to simulate in-vivo saliva conditions. A magnetic stirrer provided with temperature control was used to maintain the temperature of phosphate buffer $(\mathrm{pH} 6.8)$ in glass dish at $37 \pm 0.5^{\circ} \mathrm{C}$. A piece of rabbit intestinal mucosa, $3 \mathrm{~cm}$ long, was tightly secured on the upper surface of the acrylate tissue mounting stage with thread. Films were fixed on the centre of the formulation holding glass plate with an adhesive. The exposed film surface was moistened with phosphate buffer $(\mathrm{pH}$ 6.8) and left for $30 \mathrm{~s}$ for initial hydration and swelling. Then glass plate (with the film) was kept on the mucosal tissue secured on the tissue mounting stage in such a way that films completely remained in contact with mucosa. The whole assembly was kept undisturbed for $3 \mathrm{~min}$ (preload time) to establish the adhesion between the film and mucosal tissue. The glass plate (weight $50 \mathrm{~g}$ ) itself acted as a preload. After the preload time, water collecting pan was suspended to the left arm and water was added in it, by the siphon tube, at a constant rate of $\mathbf{2 0 0}$ drops per minute until detachment of the film from mucosal surface took place. A support was kept under the water collecting pan to hold it at the time of detachment. Weight of water collected in the pan at the time of detachment was measured. The experiment was performed in triplicate.

\subsubsection{Residence Time}

The in-vitro residence time was determined using a locally modified USP disintegration apparatus. The medium was composed of $500 \mathrm{ml}$ phosphate buffer $\left(\mathrm{pH} \mathrm{6.8)}\right.$ in $1 \mathrm{~L}$ beaker and maintained at $37 \pm 0.5^{\circ} \mathrm{C}$. A segment of gout buccal mucosa, $3 \mathrm{~cm}$ long, was glued on the inside curved surface of $1 \mathrm{~L}$ beaker above the level of $500 \mathrm{ml}$ phosphate buffer ( $\mathrm{pH}$ 6.8). A glass cylinder (100 $\mathrm{ml}$ ) was vertically fixed to the apparatus. The bioadhesive film was hydrated from one surface using phosphate buffer $(\mathrm{pH} \mathrm{6.8)}$ and then the hydrated surface was brought into contact with the mucosal membrane. The glass cylinder was vertically fixed to the apparatus and allowed to move up and down so that the film was completely immersed in the buffer solution at the lowest point and was out at the highest point. The time necessary for complete erosion or detachment of the film from the mucosal surface was recorded (mean of triplicate determinations).

\subsubsection{Stability Study:}

Stability study was carried out as per ICH guideline at $40{ }^{\circ} \mathrm{C} / 75 \% \mathrm{RH}$ conditions. Each piece of the films of formulation was packed in butter paper followed by aluminum foil and plastic tape. After 1 month, the films were evaluated for the physical appearance, drug content and in vitro drug release.

6 RESULT AND DISCUSSION

\subsection{PRE FORMULATION STUDIES}

\subsubsection{CHARACTERIZATION OF DRUG (SAXAGLIPTIN)}

Table 5: Characteristic Properties of Saxagliptin

\begin{tabular}{|c|c|c|c|}
\hline Sr. No. & \multicolumn{2}{|c|}{ Characteristic Properties } & Observation/Result \\
\hline 1 & \multirow{2}{*}{$\begin{array}{l}\text { Organoleptic } \\
\text { Characteristics }\end{array}$} & Colour & White to Off-White Solid Powder \\
\hline 2 & & Odour & Odorless \\
\hline 4 & \multirow{5}{*}{ Flow Properties } & $\begin{array}{l}\text { Bulk density } \\
(\mathrm{g} / \mathrm{ml})\end{array}$ & 0.292 \\
\hline 5 & & $\begin{array}{l}\text { Tapped density } \\
(\mathrm{g} / \mathrm{ml})\end{array}$ & 0.429 \\
\hline 6 & & Carr's index (\%) & 31.93 \\
\hline 7 & & Hausner's ratio & 1.46 \\
\hline 8 & & Angle of repose $\left(\theta^{\circ}\right)$ & $28.14^{\circ}$ \\
\hline 9 & Solubility & & $\begin{array}{l}\text { Soluble in Water and } 6.8 \\
\text { Phosphate buffer. }\end{array}$ \\
\hline
\end{tabular}


$\checkmark$ Based on above physical characterization of API it concluded that the API has a very poor flow itself but in film preparation it's not require.

Further API has a good solubility in water and it's a BCS class III molecule so solubility enhancement also not require. Low dose of API easily maintains sink condition so no any issue regarding solubility.

\subsection{DRUG EXCIPIENTS COMPATIBILITY STUDY}

\subsubsection{FTIR Study}

FTIR Study of Pure drug and Final Formulation done and results attached in below figure 1 and 2. From the below results it concluded that no any interaction found between drug and Excipients.

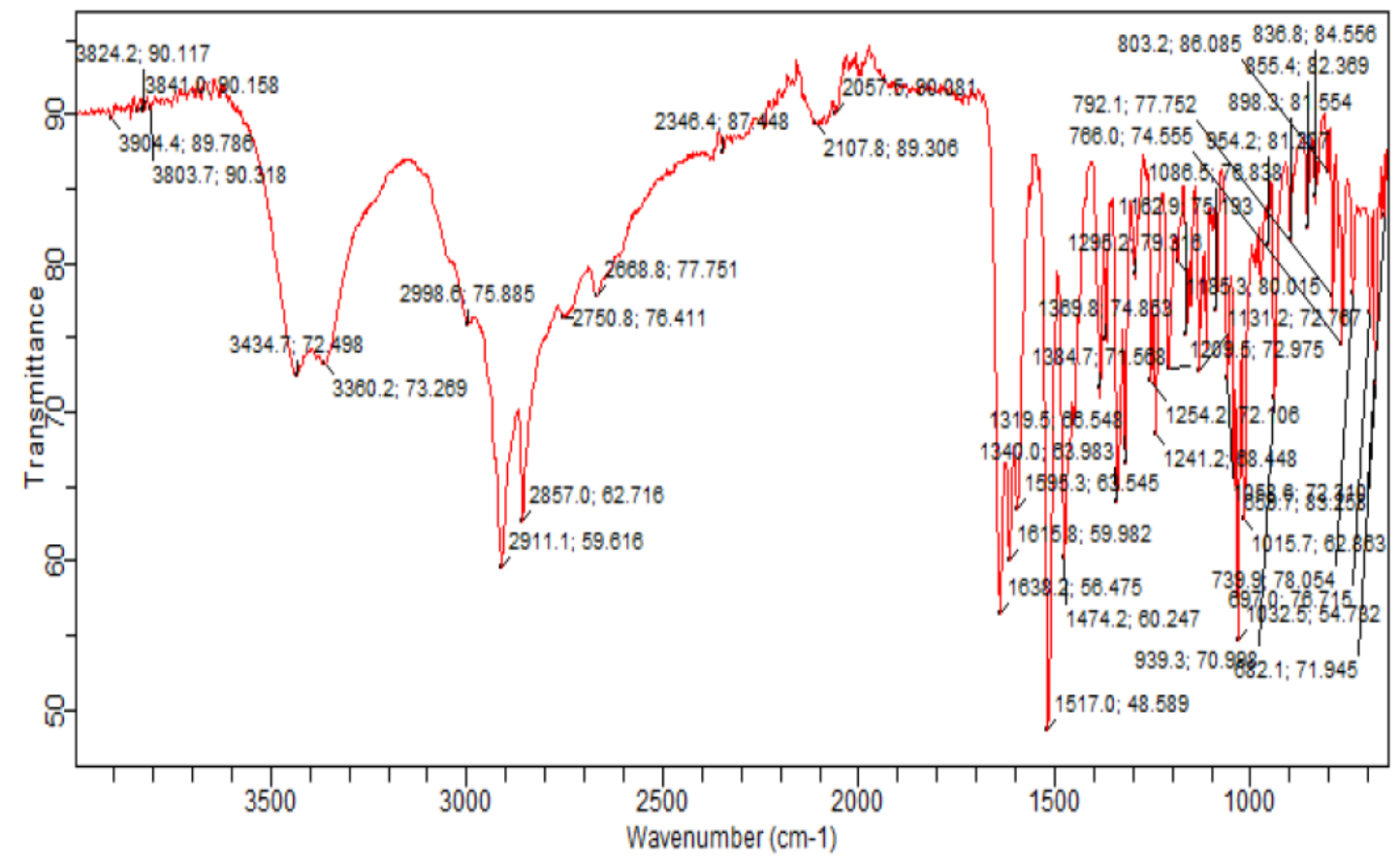

Figure 1: FTIR Spectra of Pure Drug Saxagliptin

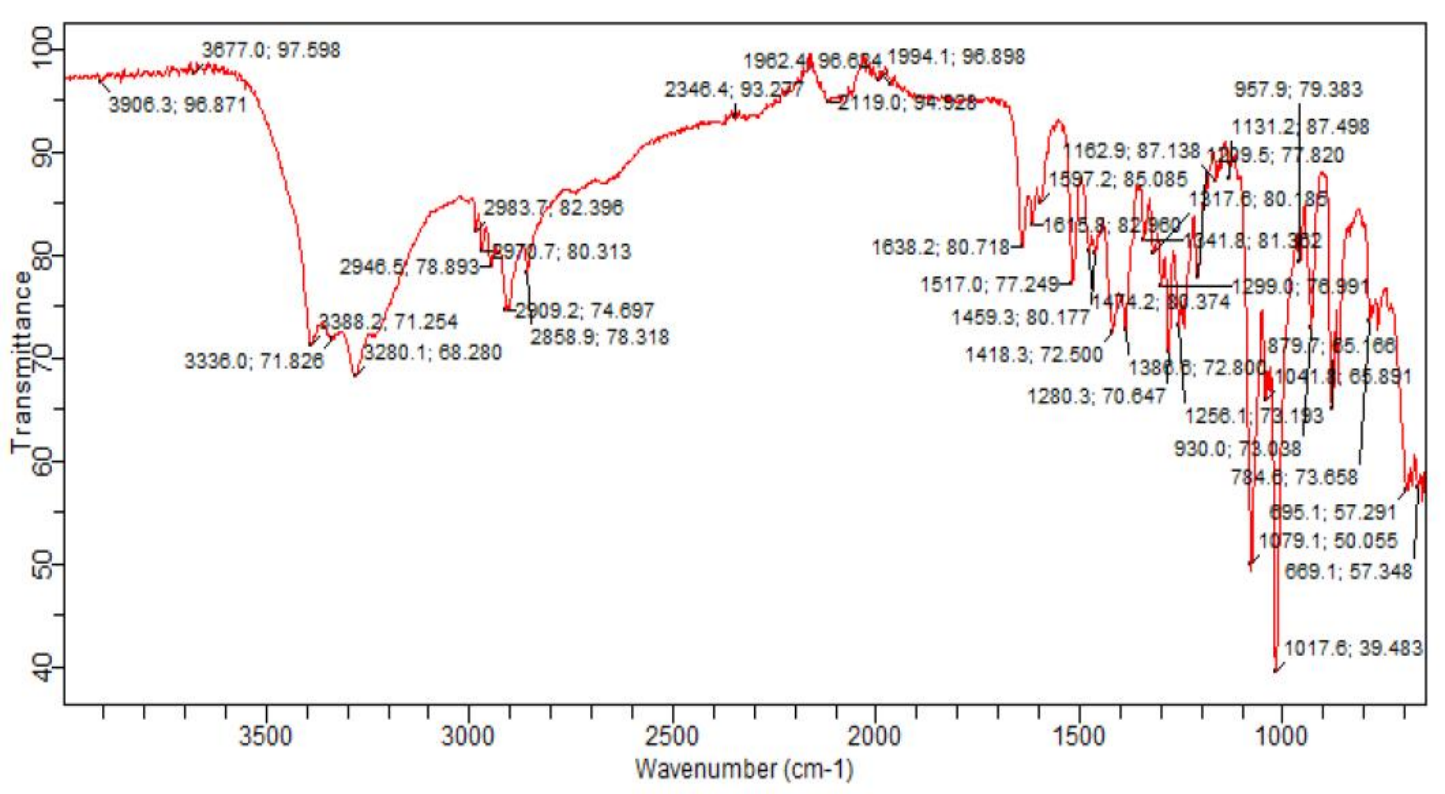

Figure 2 FTIR Spectra of Final Formulation 
Mr. Vipul Pandit, et al, Journal of Pharmaceutical and Biological Science Archive

Table 6: FTIR Data of Saxagliptin and Final Formulation

\begin{tabular}{|l|l|l|l|l|l|}
\hline \multirow{2}{*}{ IR Spectra } & \multicolumn{4}{|l|}{ Peak of functional group [Wavelength] $\mathrm{cm}^{-1}$} \\
\cline { 2 - 6 } & $\begin{array}{l}\text { O-H } \\
\text { Stretching }\end{array}$ & $\begin{array}{l}\text { C-O } \\
\text { Stretching }\end{array}$ & C=O & C-C Stretching & N-H Bend \\
\hline Saxagliptin & 2862.89 & 1152.16 & 1715.12 & 1441.93 & 1612.82 \\
\hline $\begin{array}{l}\text { Final } \\
\text { Formulation }\end{array}$ & 2942.16 & 1149.79 & 1719.03 & 1459.16 & 1612.84 \\
\hline
\end{tabular}

Saxagliptin pure drug characteristic peak observed in final formulation also. It means that no any interaction between drug and excipients found. So drug is compatible with excipients.

\subsection{Calibration curve of Saxagliptin}

The calibration curve of Saxagliptin was found to over a concentration range $2-10 \mu \mathrm{g} / \mathrm{ml} .\left(R^{2}=0.999\right)$ the data for calibration curve is given in table 8 and the calibration curve is shown in fig. 3 .

Table 7: Calibration curve of Saxagliptin in 6.8 Phosphate buffer at $208 \mathrm{~nm}$

\begin{tabular}{|l|l|l|}
\hline Sr. No & Concentration $(\mu \mathrm{g} / \mathrm{ml})$ & $\begin{array}{l}\text { Absorbance } \pm \text { SD } \\
(\mathbf{n}=3)\end{array}$ \\
\hline 1 & 0 & 0 \\
\hline 2 & 2 & $0.149 \pm 0.003$ \\
\hline 3 & 4 & $0.273 \pm 0.002$ \\
\hline 4 & 6 & $0.443 \pm 0.003$ \\
\hline 5 & 8 & $0.569 \pm 0.002$ \\
\hline 6 & 10 & $0.712 \pm 0.003$ \\
\hline 7 & 12 & $0.853 \pm 0.003$ \\
\hline
\end{tabular}

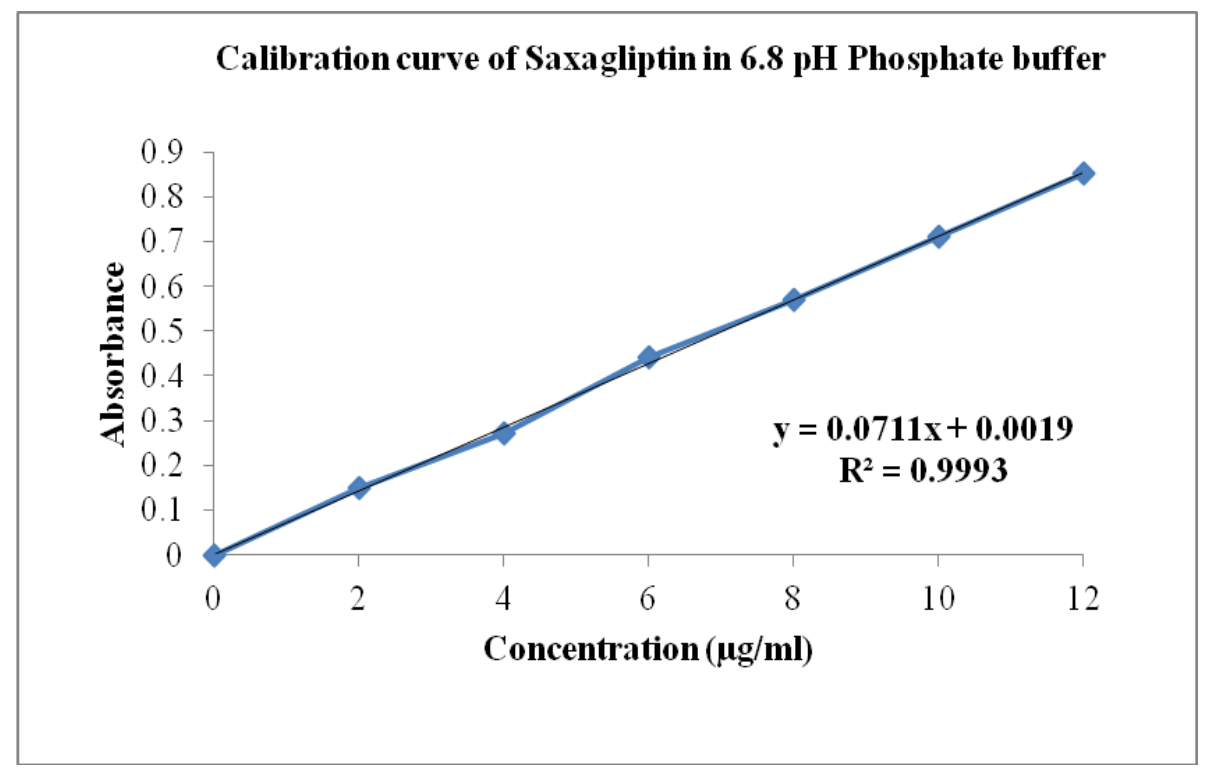

Figure 3 Calibration curve of Saxagliptin in 6.8 Phosphate buffer at $208 \mathrm{~nm}$ 


\subsection{EVALUATION OF SAXAGLIPTIN BUCCAL FILMS:}

Trial batches of Saxagliptin Buccal films were evaluated for various parameters and the results were recorded. To get the tentative idea of formulation, only few important parameters were evaluated from the trial batches.

Weight variation study for four trial batches F1-F4 checked and found well within acceptable limit.

Thickness of the F1-F4 formulation found around 0.98 to $1.02 \mathrm{~mm}$.

Folding endurance of all batches found more than 300. It means all the formulations were good strength and the batch F4 in which two polymers were used have 406 folding endurance. The films were good flexible and appearance was also good.

The surface $\mathrm{pH}$ of the trial batches F1-F4 found 6.6-7.1. It was clearly indicated that the neutral pH range not affect the buccal mucosa.

Table 8 Evaluation parameters of F1-F4 trial batches

\begin{tabular}{|l|l|l|l|l|}
\hline Formulation & $\begin{array}{l}\text { Weight variation } \\
\text { (mg) }\end{array}$ & Thickness $(\mathbf{m m})$ & $\begin{array}{l}\text { Folding } \\
\text { Endurance }\end{array}$ & Surface $\mathbf{p H}$ \\
\hline F1 & $429 \pm 3.5$ & $0.98 \pm 0.21$ & $386 \pm 15$ & $7.1 \pm 0.4$ \\
\hline F2 & $456 \pm 5.8$ & $1.02 \pm 0.16$ & $395 \pm 19$ & $6.8 \pm 0.5$ \\
\hline F3 & $419 \pm 6.9$ & $0.99 \pm 0.09$ & $398 \pm 10$ & $6.6 \pm 0.2$ \\
\hline F4 & $443 \pm 5.2$ & $1.00 \pm 0.10$ & $406 \pm 21$ & $6.9 \pm 0.7$ \\
\hline
\end{tabular}

Table 9: Evaluation parameters of F1-F4 trial batches

\begin{tabular}{|l|l|l|l|l|}
\hline Formulation & Drug Content \% & $\begin{array}{l}\text { Tensile Strength } \\
\left(\mathbf{N} / \mathbf{m m}^{2}\right)\end{array}$ & \% Elongation & Swelling Index (\%) \\
\hline F1 & $96.8 \pm 0.9$ & $3.14 \pm 0.19$ & $31.99 \pm 2.95$ & $28.2 \pm 0.24$ \\
\hline F2 & $98.5 \pm 0.5$ & $3.06 \pm 0.33$ & $33.65 \pm 3.65$ & $31.5 \pm 0.10$ \\
\hline F3 & $98.2 \pm 0.6$ & $3.56 \pm 0.20$ & $38.96 \pm 1.58$ & $33.9 \pm 0.39$ \\
\hline F4 & $98.9 \pm 0.3$ & $3.68 \pm 0.28$ & $41.68 \pm 2.87$ & $36.8 \pm 0.25$ \\
\hline
\end{tabular}

Drug content (assay) found satisfactory in F1-F4 batch. The assay range was 96.8-98.9 in all trial batches. Assay results revealed that the drug distribution was uniform in all formulation.

Swelling index was more than $25 \%$ after 8 hour. The single polymer has a $28.2 \%$ and the value was increase as the amount of second polymer added.

Tensile strength was measured and recorded in above table. All formulation has a good tensile strength and $\%$ elongation. F4 formulation has a maximum $41 \%$ of elongation among all formulations.

Dissolution study of trial batches F1-F4 performed and the results were recorded in below table. The results of drug release study revealed that the $\mathrm{F} 1$ batch which contains the single polymer sodium alginate was not retard the release up to 8 hour and complete the drug release in 6 hours. So to retard the release rate addition Chitosan polymer added and the F2 batch retard the release compared to F1 batch and the batch retard up to 8 hours. F3 batch taken with addition of more Chitosan to retard the release and hence the F3 formulation release up to 8 hours. Still the desired theoretical release profile not achieved and hence again one more batch F4 was taken with higher amount of Chitosan. The drug release of F4 was near to the theoretical release profile and hence the F4 formulation was decided to take for factorial design application and optimization of polymer amount. 
Table 10: Dissolution study of Trial batches F1-F4

\begin{tabular}{|l|l|l|l|l|l|}
\hline Time (hour) & $\mathbf{1}$ & $\mathbf{2}$ & $\mathbf{4}$ & $\mathbf{6}$ & $\mathbf{8}$ \\
\hline F1 & $43.9 \pm 5.9$ & $58.3 \pm 3.8$ & $81.3 \pm 2.6$ & $96.5 \pm 1.6$ & $99.1 \pm 1.1$ \\
\hline F2 & $41.2 \pm 3.5$ & $55.6 \pm 5.6$ & $76.8 \pm 1.9$ & $95.3 \pm 0.9$ & $98.6 \pm 0.6$ \\
\hline F3 & $36.7 \pm 2.8$ & $53.4 \pm 4.2$ & $73.9 \pm 2.7$ & $92.6 \pm 1.8$ & $96.8 \pm 1.5$ \\
\hline F4 & $33.8 \pm 5.7$ & $45.9 \pm 3.3$ & $69.7 \pm 3.9$ & $85.9 \pm 1.7$ & $98.9 \pm 0.5$ \\
\hline
\end{tabular}

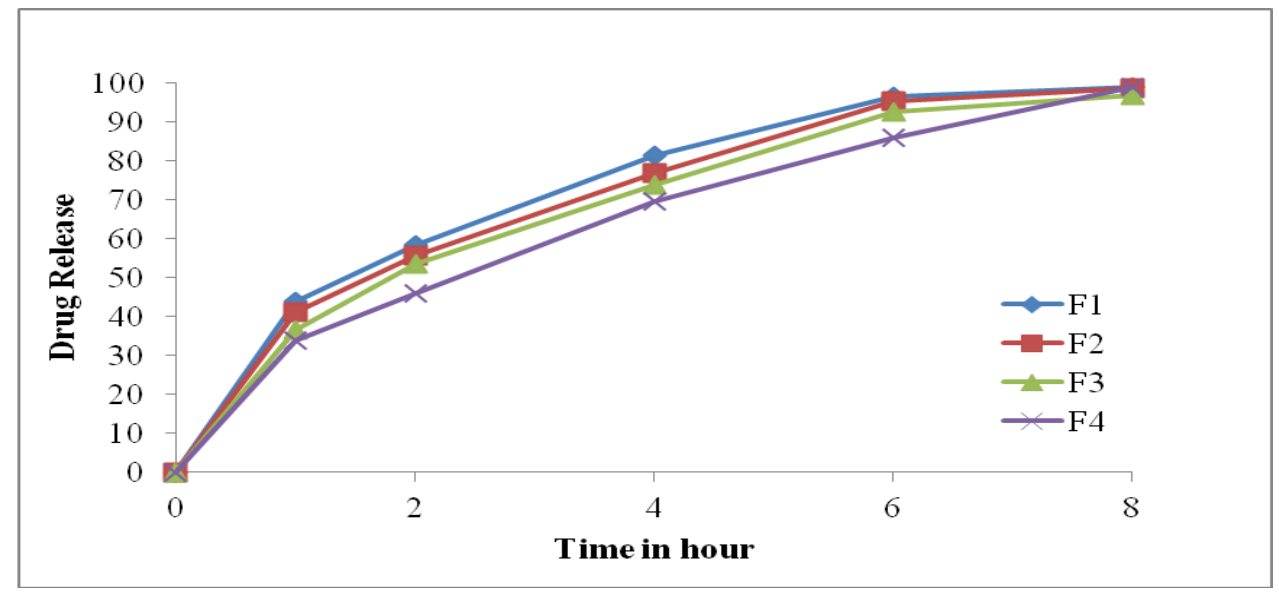

Figure 4: Dissolution comparison of trial batches F1-F4

\subsection{FACTORIAL DESIGN FOR FORMULA OPTIMIZATION}

Based on trial batches results, $2^{3}$ full factorial design was selected to apply for formula optimization. 3 factors and 2 level design selected and the selected factors and their level were shown in below table.

Table 11: Factors and Level for factorial design

\begin{tabular}{|l|l|l|l|}
\hline Factor & \multicolumn{2}{l|}{ Level } & 750 \\
\hline X1 & Sodium Alginate (mg) & 650 & 350 \\
\hline X2 & Chitosan (mg) & 250 & 20 \\
\hline X3 & PEG 400 (ml) & 10 & \\
\hline
\end{tabular}

Table 12: Formulation table for factorial batches

\begin{tabular}{|l|l|l|l|l|l|l|l|l|}
\hline Ingredients (mg/film) & F5 & F6 & F7 & F8 & F9 & F10 & F11 & F12 \\
\hline Saxagliptin & 8.0 & 8.0 & 8.0 & 8.0 & $\mathbf{8 . 0}$ & 8.0 & 8.0 & 8.0 \\
\hline Sodium Alginate & 750 & 750 & 750 & 750 & 650 & 650 & 650 & 650 \\
\hline Chitosan & 250 & 250 & 350 & 350 & 350 & 250 & 350 & 250 \\
\hline PEG 400 (ml) & 10 & 20 & 20 & 10 & 20 & 20 & 10 & 10 \\
\hline Acesulfame Potassium & 5 & 5 & 5 & 5 & $\mathbf{5}$ & 5 & 5 & 5 \\
\hline Water (ml) & Q.S & Q.S & Q.S & Q.S & Q.S & Q.S & Q.S & Q.S \\
\hline
\end{tabular}

Prepared factorial batches were evaluated as per evaluation methods given in Chapter 5. 


\subsection{ANALYSIS OF FACTORIAL BATCHES F5-F12}

Completed analysis of factorial batches F5-F12 was done and the results were recorded in this section. Physical and chemical evaluation parameters were checked for factorial batches and results were recorded in below tables.

Weight variation was found well within acceptable limit. Weight of individual film was high when the amount of polymer was increased. Thickness was in range of $1.00 \mathrm{~mm}$. folding endurance was good enough in all formulation. Most of the formulation has more than 400 value of folding endurance. Surface $\mathrm{pH}$ was found almost neutral hence no any irritation effect on mucosa.

Drug content values were found satisfactory. It was found that the drug was properly distributed in films during preparation. Tensile strength was found between $3-4 \mathrm{~N} / \mathrm{mm}^{2}$ which was good enough for mucoadhesion properties and which impacts on \% elongation were directly. All films were good flexible in nature and \% elongation was found around $40 \%$. Swelling capacity of films were good and the $\%$ swelling was around $30-40 \%$.

Residence time for films was more than 6 hour in all formulation. F9 formulation has 8 hour residence time. Mucoadhesion strength was found good enough in factorial batches. All formulation has more than $300 \mathrm{~g}$ mucoadhesion value. This is because of the sodium alginate have a good mucoadhesive properties. Additionally the addition of Chitosan was improves the mucoadhesion as well as residence time properties of films. Based on results it concluded that the combination of two polymers improves the mucoadhesion properties in the films. Further screening was also done for mucoadhesive strength using ANOVA.

All the evaluation parameters of factorial batches were recorded below including the graphical comparison.

Table 13 Evaluation parameters of F5-F12 factorial batches

\begin{tabular}{|l|l|l|l|l|}
\hline Formulation & $\begin{array}{l}\text { Weight variation } \\
(\mathbf{m g})\end{array}$ & Thickness $(\mathbf{m m})$ & $\begin{array}{l}\text { Folding } \\
\text { Endurance }\end{array}$ & Surface pH \\
\hline F5 & $449 \pm 2.9$ & $0.99 \pm 0.35$ & $406 \pm 18$ & $6.9 \pm 0.3$ \\
\hline F6 & $453 \pm 5.6$ & $0.98 \pm 0.21$ & $449 \pm 16$ & $6.5 \pm 0.7$ \\
\hline F7 & $503 \pm 3.7$ & $1.02 \pm 0.15$ & $486 \pm 11$ & $7.0 \pm 0.3$ \\
\hline F8 & $506 \pm 3.9$ & $1.05 \pm 0.08$ & $462 \pm 13$ & $6.9 \pm 0.2$ \\
\hline F9 & $532 \pm 1.8$ & $0.98 \pm 0.13$ & $409 \pm 21$ & $6.8 \pm 0.4$ \\
\hline F10 & $465 \pm 5.4$ & $0.99 \pm 0.18$ & $386 \pm 19$ & $7.1 \pm 0.1$ \\
\hline F11 & $473 \pm 4.6$ & $0.96 \pm 0.16$ & $400 \pm 10$ & $6.8 \pm 0.3$ \\
\hline F12 & $410 \pm 7.2$ & $0.99 \pm 0.21$ & $371 \pm 13$ & $7.3 \pm 0.2$ \\
\hline
\end{tabular}



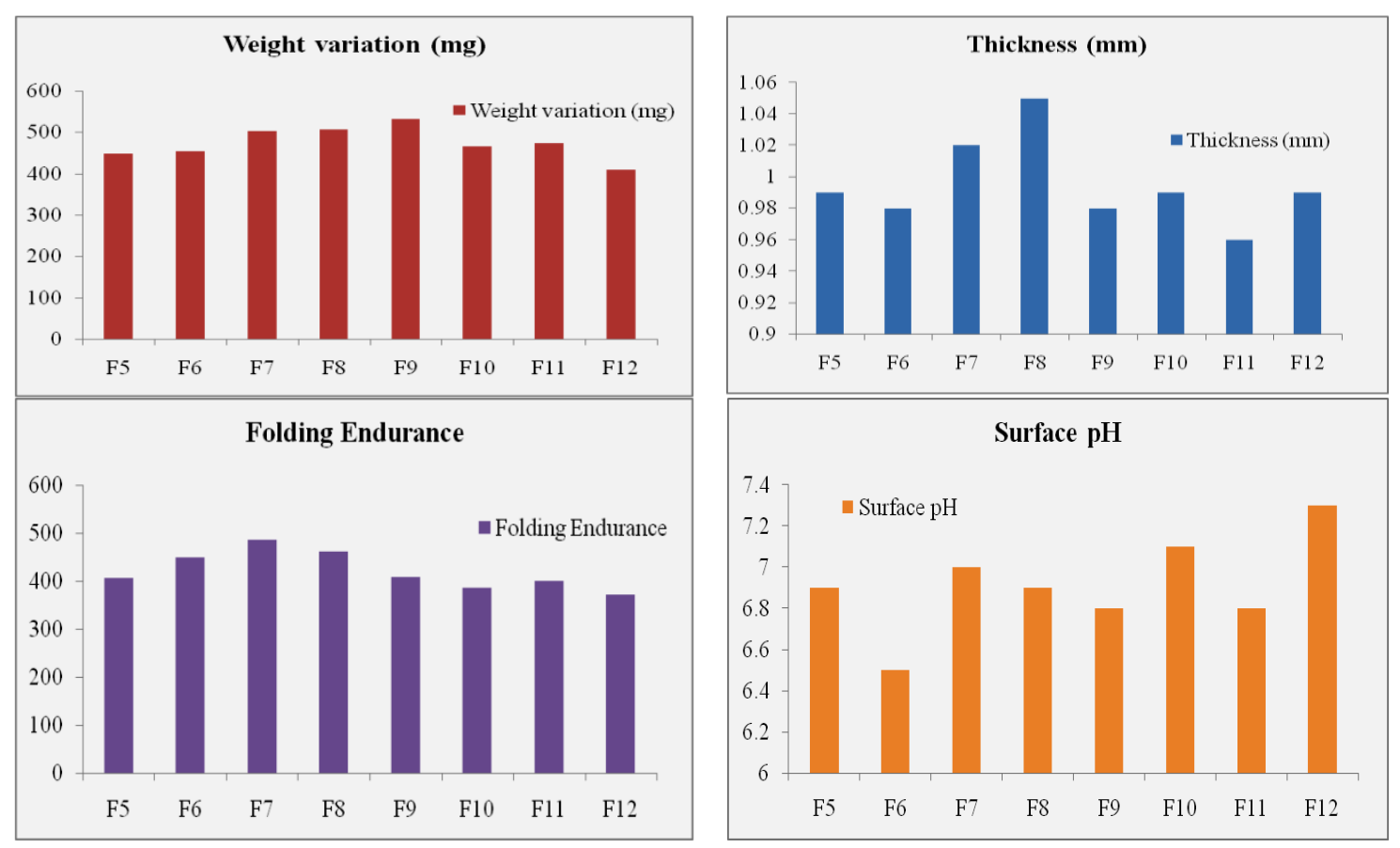

Figure 5: Evaluation parameters of F5-F12 factorial batches

Table 14 Evaluation parameters of F5-F12 factorial batches

\begin{tabular}{|l|l|l|l|l|}
\hline Formulation & Drug Content \% & $\begin{array}{l}\text { Tensile Strength } \\
\left(\mathrm{N} / \mathrm{mm}^{2}\right)\end{array}$ & Swelling Index (\%) \\
\hline F5 & $98.3 \pm 1.5$ & $3.65 \pm 0.85$ & $41.32 \pm 2.75$ & $36.4 \pm 0.52$ \\
\hline F6 & $96.8 \pm 3.9$ & $3.79 \pm 0.65$ & $45.93 \pm 1.96$ & $35.9 \pm 0.41$ \\
\hline F7 & $95.9 \pm 4.6$ & $3.85 \pm 0.54$ & $48.65 \pm 2.54$ & $39.5 \pm 0.36$ \\
\hline F8 & $98.6 \pm 3.5$ & $3.76 \pm 0.96$ & $46.54 \pm 3.64$ & $40.3 \pm 0.64$ \\
\hline F9 & $99.2 \pm 2.3$ & $3.93 \pm 1.05$ & $40.32 \pm 1.87$ & $41.8 \pm 0.56$ \\
\hline F10 & $98.9 \pm 1.9$ & $3.61 \pm 0.63$ & $36.51 \pm 2.95$ & $38.6 \pm 0.47$ \\
\hline F11 & $97.6 \pm 2.5$ & $3.75 \pm 0.50$ & $38.61 \pm 1.67$ & $43.6 \pm 0.27$ \\
\hline F12 & $96.8 \pm 3.4$ & $3.55 \pm 0.48$ & $34.36 \pm 2.30$ & $42.9 \pm 0.74$ \\
\hline
\end{tabular}


Mr. Vipul Pandit, et al, Journal of Pharmaceutical and Biological Science Archive
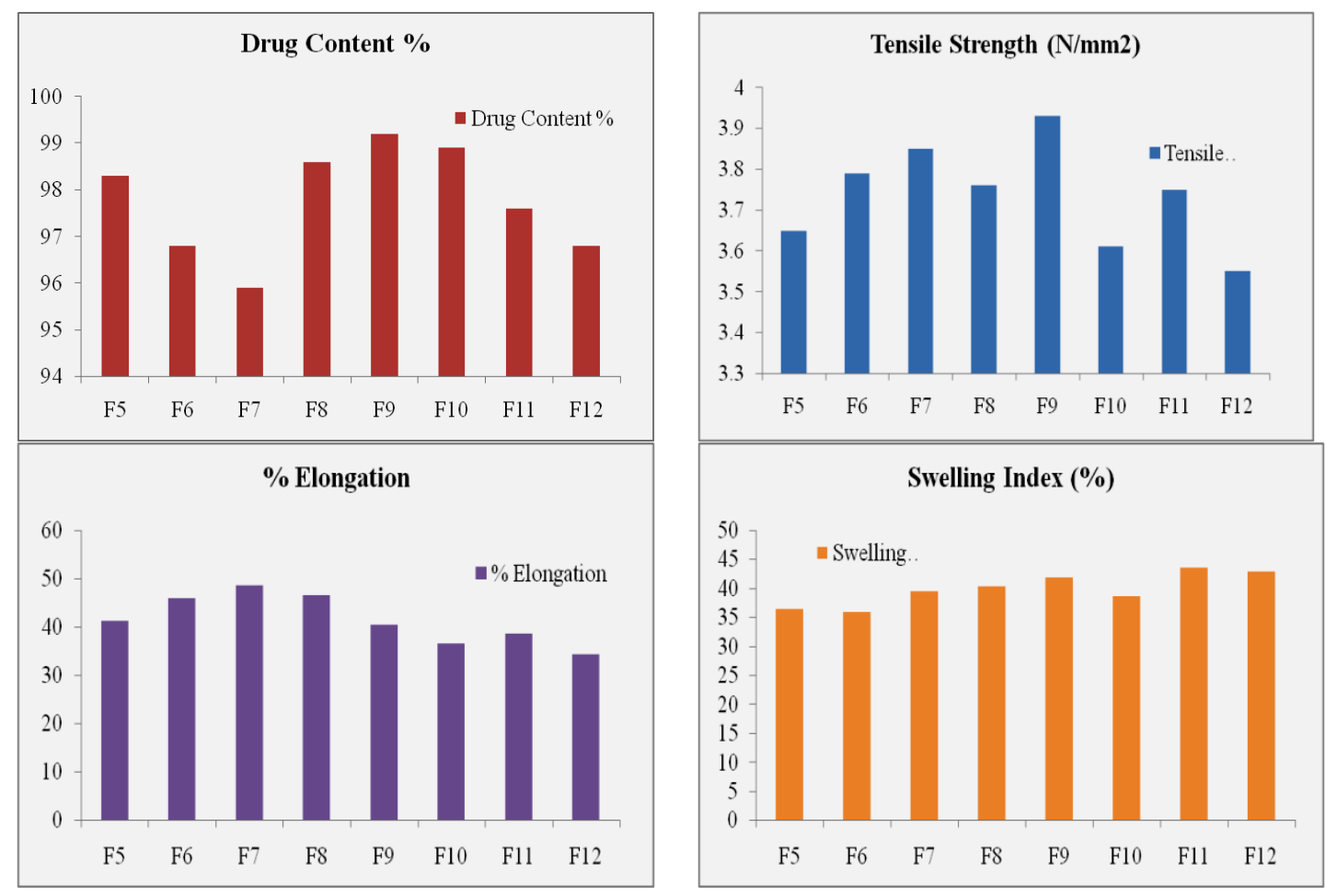

Figure 6: Evaluation parameters of F5-F12 factorial batches

Table 15: Evaluation parameters of F5-F12 factorial batches

\begin{tabular}{|l|l|l|}
\hline Formulation & Mucoadhesion force (g) & Residence time (hour) \\
\hline F5 & $486 \pm 11$ & 6 \\
\hline F6 & $493 \pm 23$ & 6 \\
\hline F7 & $523 \pm 19$ & 8 \\
\hline F8 & $515 \pm 10$ & 8 \\
\hline F9 & $496 \pm 09$ & 8 \\
\hline F10 & $323 \pm 16$ & 6 \\
\hline F11 & $471 \pm 08$ & 8 \\
\hline F12 & $310 \pm 18$ & 6 \\
\hline
\end{tabular}




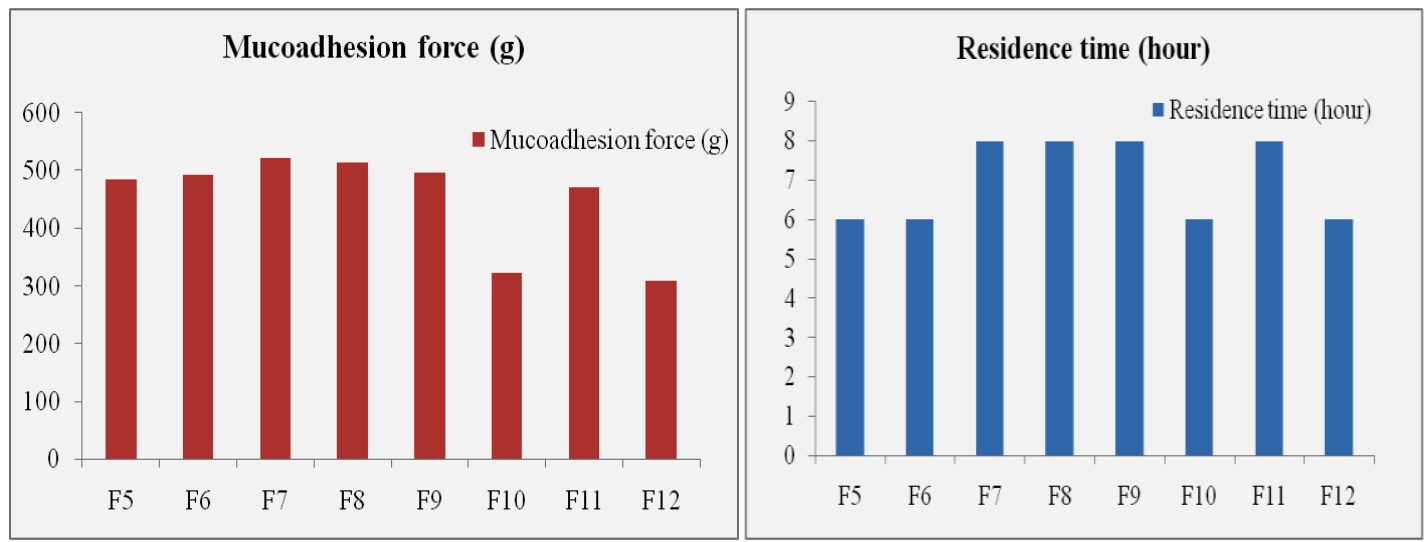

Figure 7: Evaluation parameters of F5-F12 factorial batches

Dissolution study was one of the most key parameter for buccal films formulation. As discussed earlier, for this formulation a predetermined theoretical drug release profile was set. The optimization was done considering that release profile. Here in combination of two polymers, it seems that the amount of Chitosan was significantly retarding the drug release. Hence the batch which contains $650 \mathrm{mg}$ of sodium alginate and $350 \mathrm{mg}$ of Chitosan was best fitted with the targeted release profile. Hence the batch F9 was found most satisfactory among all batches. Hence the F9 was the optimized batch.

Table 16 Dissolution study of factorial batches F5-F12

\begin{tabular}{|l|l|l|l|l|l|}
\hline Time (hour) & $\mathbf{1}$ & $\mathbf{2}$ & 4 & 6 & 8 \\
\hline F5 & $34.1 \pm 6.8$ & $46.9 \pm 4.1$ & $68.1 \pm 3.6$ & $86.2 \pm 1.8$ & $98.8 \pm 0.4$ \\
\hline F6 & $37.5 \pm 5.9$ & $52.6 \pm 3.0$ & $76.9 \pm 7.9$ & $88.7 \pm 2.3$ & $99.5 \pm 1.1$ \\
\hline F7 & $28.5 \pm 4.7$ & $36.9 \pm 2.8$ & $55.9 \pm 4.3$ & $74.3 \pm 1.7$ & $89.5 \pm 0.9$ \\
\hline F8 & $26.3 \pm 5.1$ & $32.7 \pm 3.6$ & $50.9 \pm 2.7$ & $71.8 \pm 1.8$ & $86.1 \pm 1.3$ \\
\hline F9 & $30.5 \pm 6.0$ & $42.5 \pm 1.8$ & $61.7 \pm 1.6$ & $79.5 \pm 2.5$ & $99.1 \pm 0.5$ \\
\hline F10 & $43.6 \pm 3.7$ & $63.1 \pm 4.6$ & $81.6 \pm 3.3$ & $98.5 \pm 2.0$ & $99.3 \pm 1.6$ \\
\hline F11 & $28.2 \pm 4.9$ & $38.5 \pm 6.1$ & $60.4 \pm 2.6$ & $79.5 \pm 1.7$ & $91.3 \pm 0.2$ \\
\hline F12 & $40.8 \pm 3.9$ & $62.9 \pm 1.9$ & $79.6 \pm 4.6$ & $96.4 \pm 2.3$ & $98.7 \pm 1.3$ \\
\hline
\end{tabular}




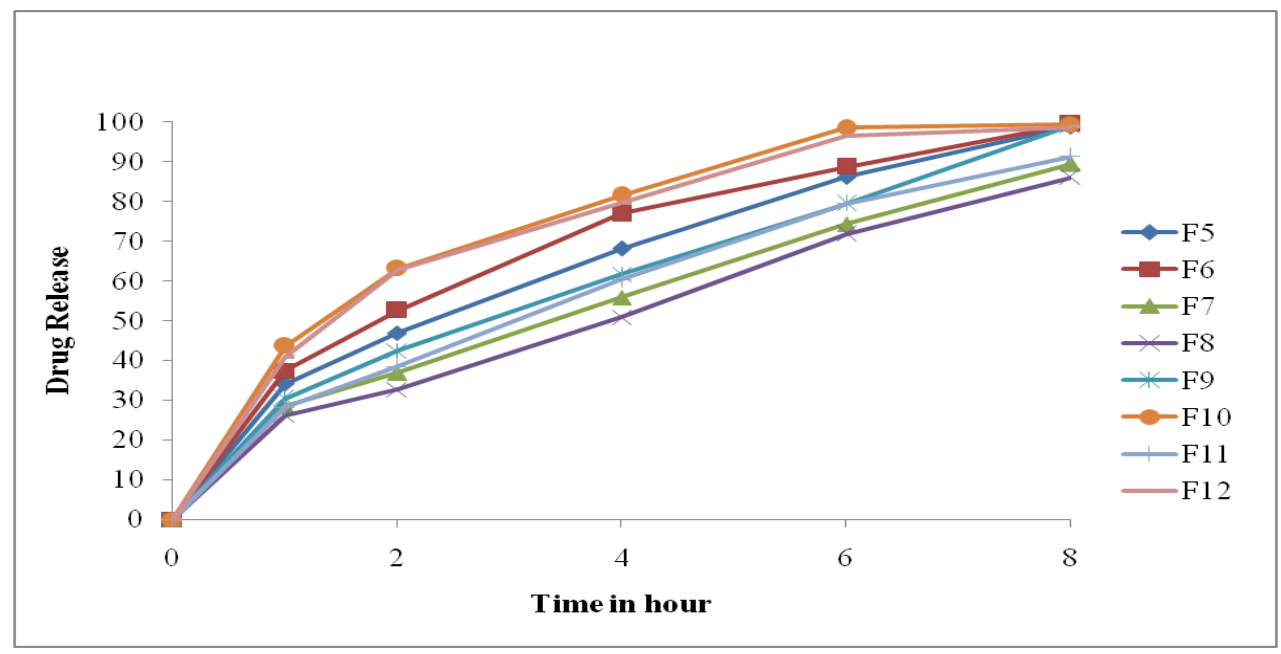

Figure 8 Dissolution comparison of F5-F12 factorial batches

Dissolution data of F9 batch fitted in different kinetic models and the $R^{2}$ value with coefficient value was recorded in below table. The most satisfactory kinetic model was Higuchi model and the $\mathrm{R}^{2}$ value was 0.990 .

Table 17 Kinetic modeling of optimized batch F9

\begin{tabular}{|l|l|l|}
\hline Kinetic Model & Parameters & Value \\
\hline Zero Order & $\mathrm{R}^{2}$ & 0.954 \\
\hline First Order & $\mathrm{K}_{0}$ & 12.75 \\
\hline & $\mathrm{R}^{2}$ & 0.805 \\
\hline Higuchi & $\mathrm{K}_{1}$ & 2.173 \\
\hline & $\mathrm{R}^{2}$ & $\mathbf{0 . 9 9 0}$ \\
\hline Korsmeyer-Peppas & $\mathrm{K}_{\mathrm{H}}$ & 3.085 \\
\hline & $\mathrm{R}^{2}$ & 0.536 \\
\hline Hixon Crowell & $\mathrm{K}_{\mathrm{P}}$ & 0.867 \\
\hline & $\mathrm{R}^{2}$ & 0.931 \\
\hline & $\mathrm{K}_{\mathrm{HC}}$ & 0.071 \\
\hline
\end{tabular}

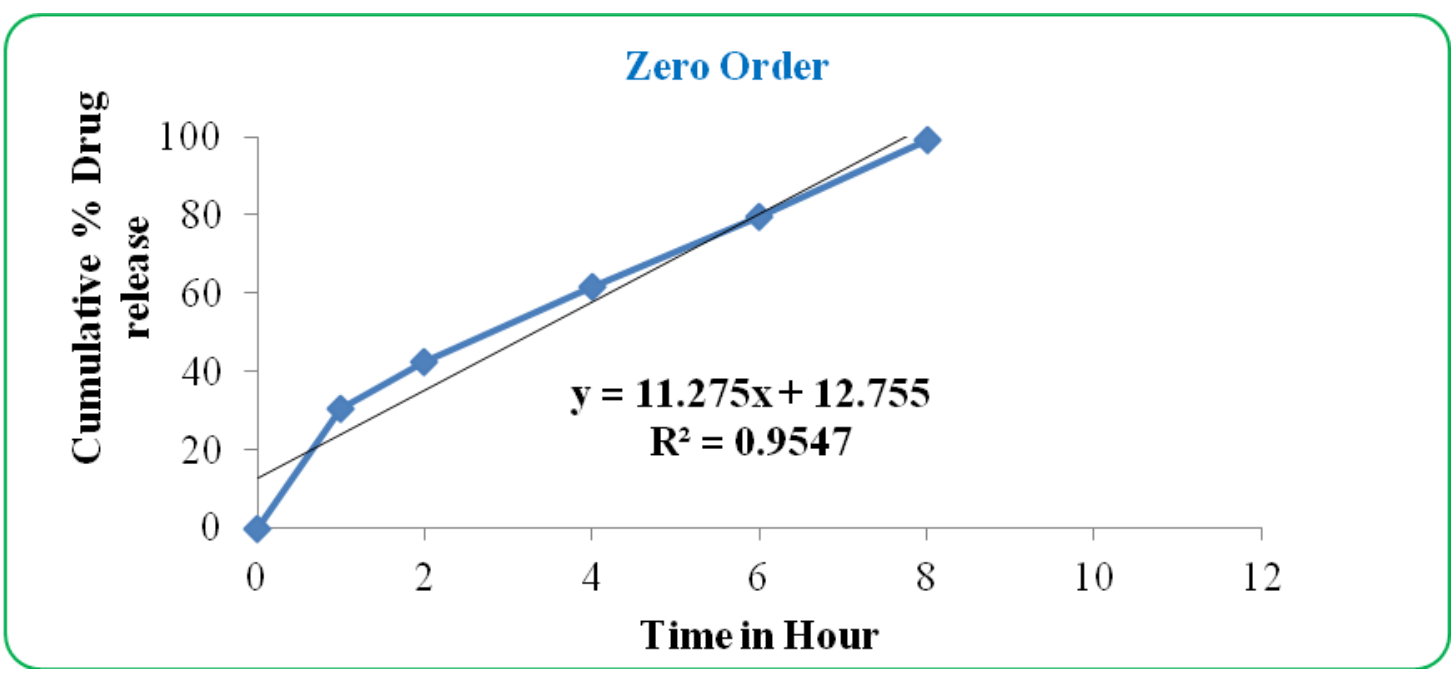



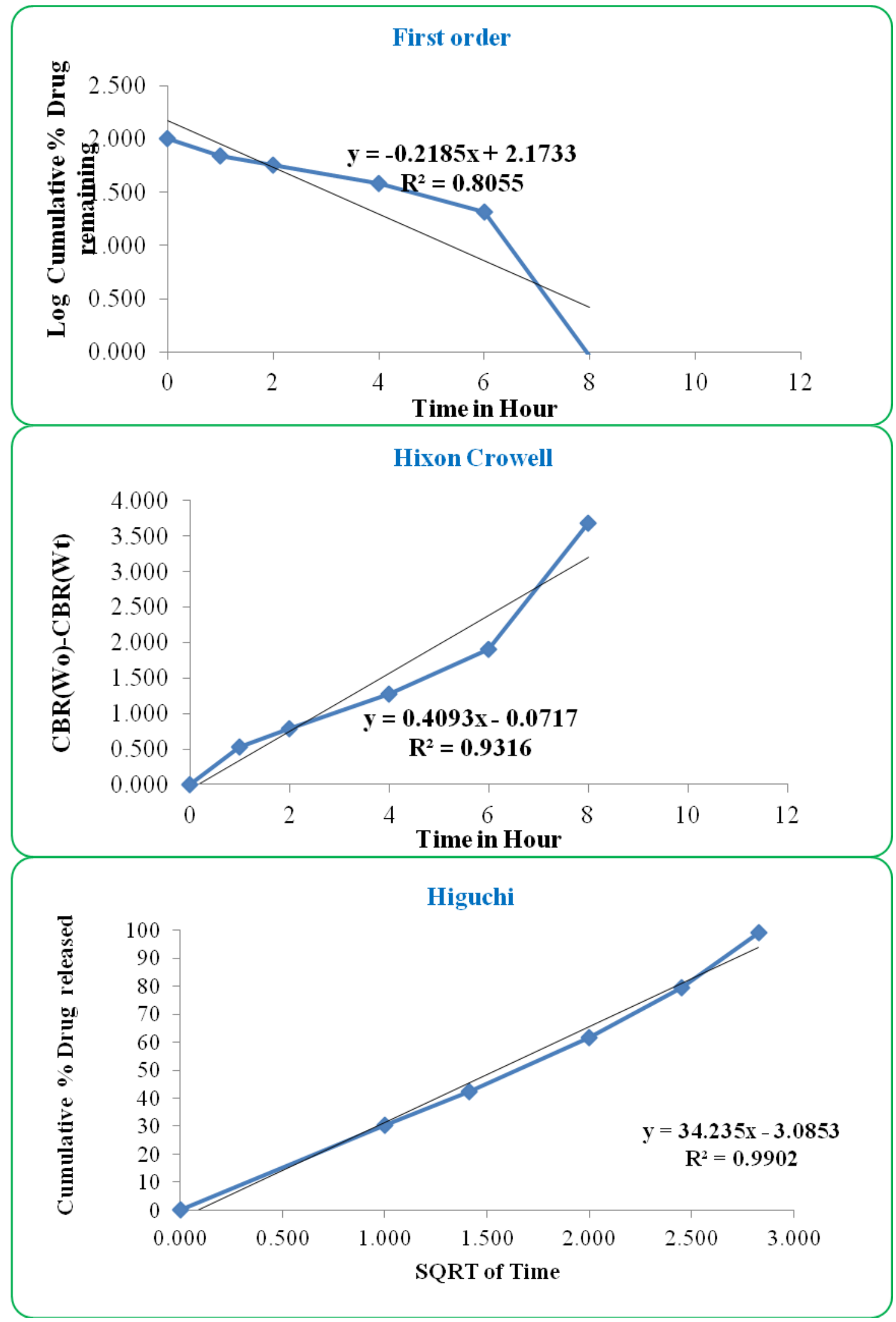


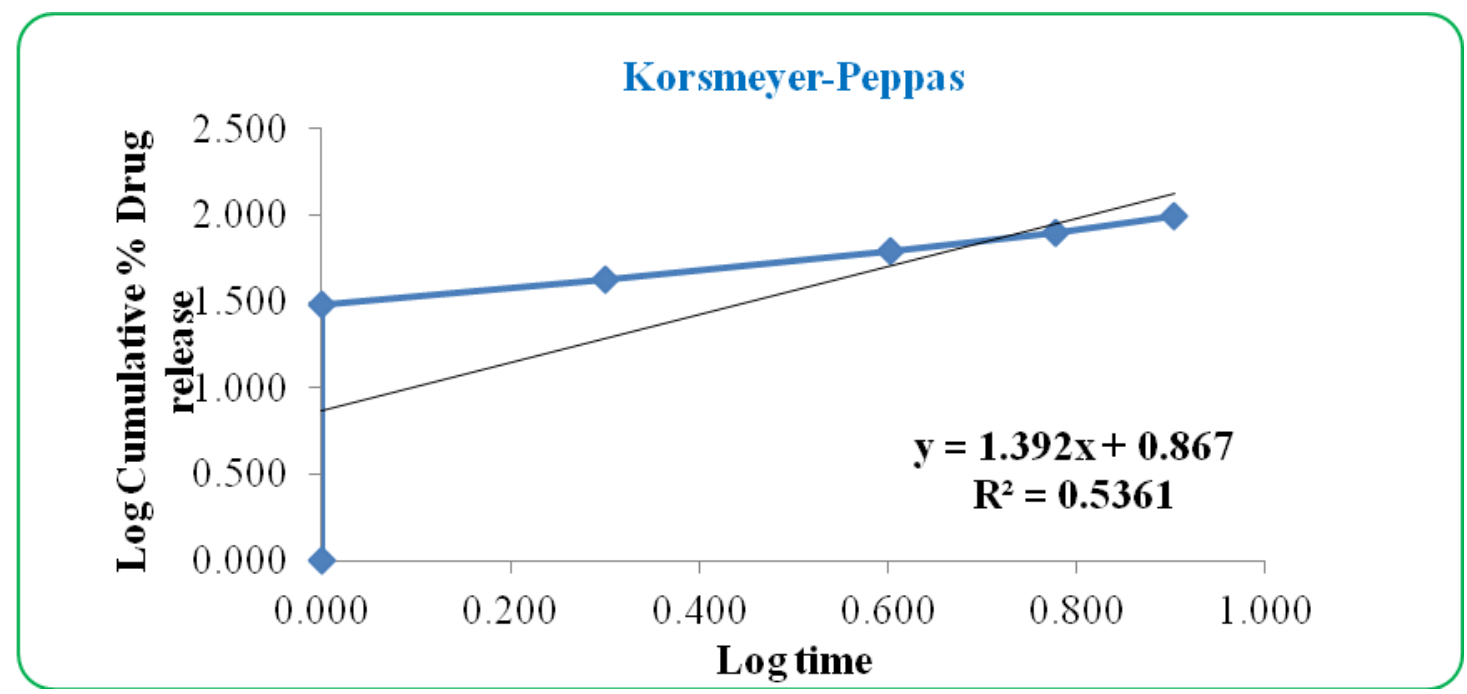

Figure 9: Kinetic modeling of optimized batch F9

Ex-Vivo permeability study of $\mathrm{F} 9$ batch performed as it was the most satisfactory batch among all. It found that the more than $90 \%$ drug was release in 8 hours. The batch was shows good permeability also. The results of permeability study and the release profile also shown below.

Table 18 Ex-vivo permeability study of optimized batch F9

\begin{tabular}{|l|l|}
\hline Time in hour & \% Drug release \\
\hline 0 & 0 \\
\hline 1 & $21.5 \pm 5.1$ \\
\hline 2 & $32.9 \pm 6.4$ \\
\hline 4 & $57.7 \pm 3.9$ \\
\hline 6 & $75.6 \pm 2.4$ \\
\hline 8 & $90.6 \pm 0.9$ \\
\hline
\end{tabular}

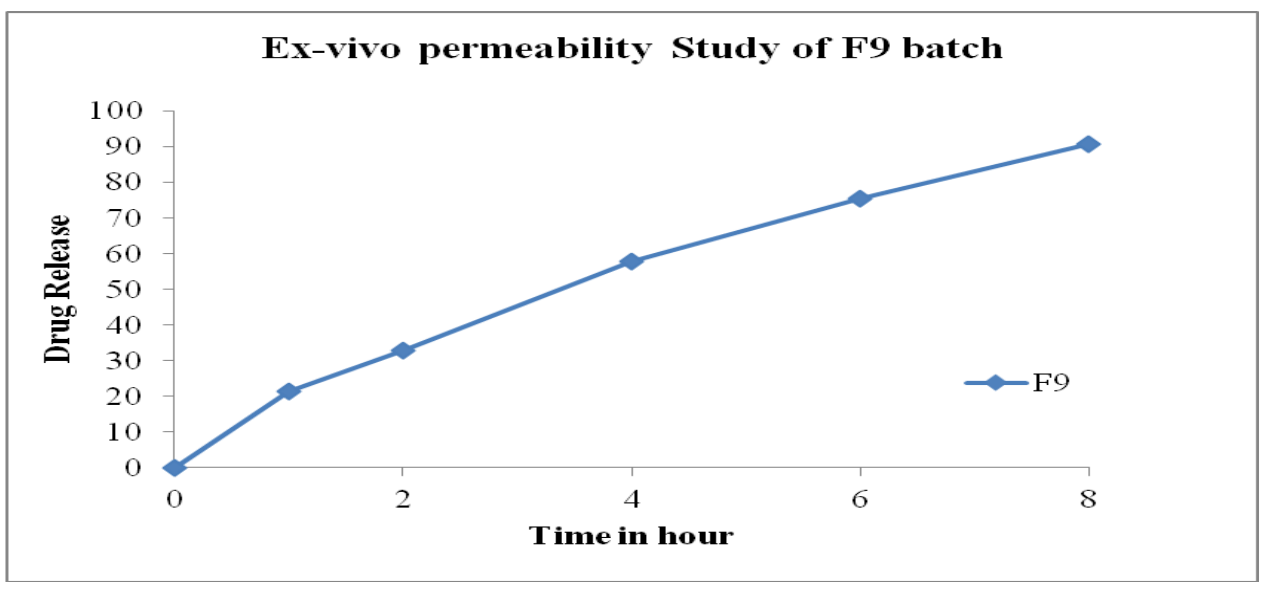

Figure 10 Permeability study of optimized batch F9 
Final batch F9 which was the most satisfactory batch in terms of drug release study as well as mucoadhesion study including residence time was subjected for comparison with the marketed formulation. Below table shows the comparative release profile and graph for F9 and Onglyza marketed product. The marketed product was convention type immediate release tables so it was release the drug within 1 hour.

Table 19 Comparison of optimized batch F9 with marketed product

\begin{tabular}{|l|l|l|l|l|l|}
\hline Time (hour) & $\mathbf{1}$ & $\mathbf{2}$ & $\mathbf{4}$ & 6 & $\mathbf{8}$ \\
\hline F9 & $30.5 \pm 6.0$ & $42.5 \pm 1.8$ & $61.7 \pm 1.6$ & $79.5 \pm 2.5$ & $99.1 \pm 0.5$ \\
\hline Onglyza & $90.6 \pm 5.9$ & $99.5 \pm 0.5$ & $99.9 \pm 0.2$ & $99.9 \pm 0.1$ & $99.9 \pm 0.1$ \\
\hline
\end{tabular}

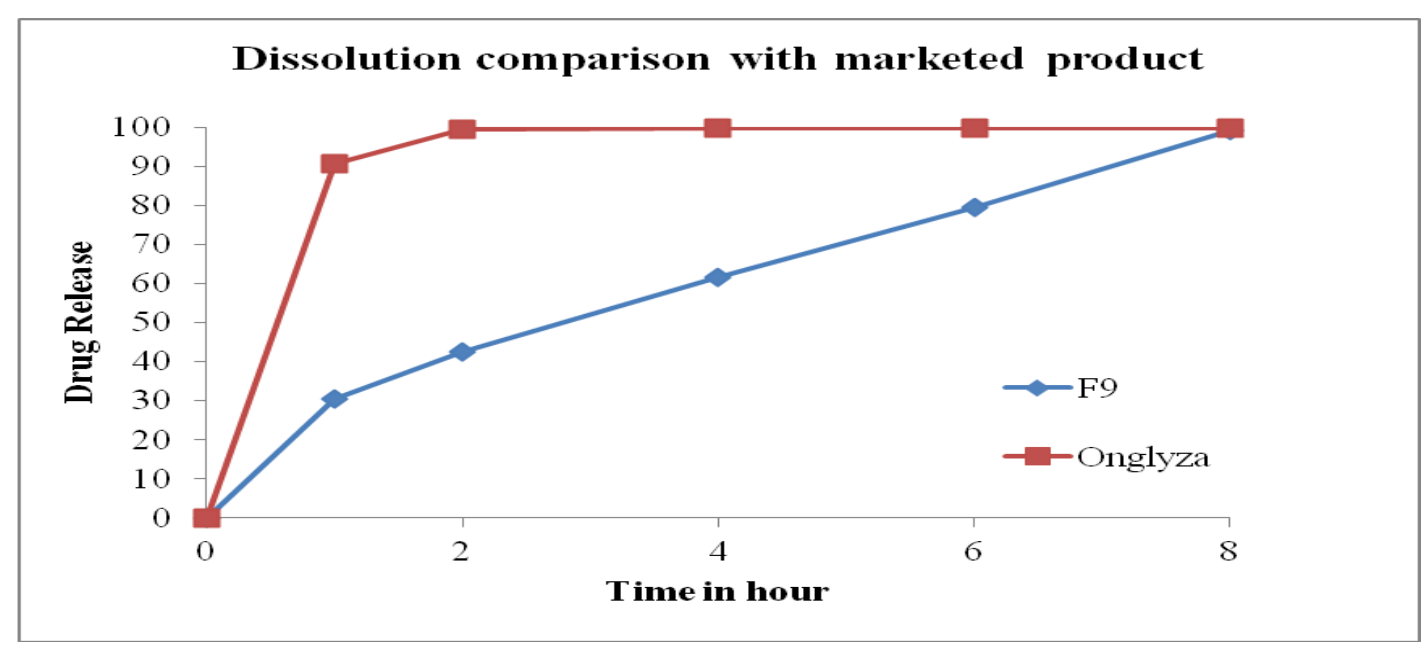

Figure 11: Comparison of optimized batch F9 with marketed product

\subsection{ANALYSIS OF FACTORIAL DESIGN}

Data obtained from the factorial batches were fitted into the selected model and the software generated Data collected for regression analysis.

Table 20 Factorial design table for data analysis

\begin{tabular}{|l|l|l|l|l|l|l|l|l|l|}
\hline $\begin{array}{l}\text { Std } \\
\text { Order }\end{array}$ & $\begin{array}{l}\text { Run } \\
\text { Order }\end{array}$ & $\begin{array}{l}\text { Pt } \\
\text { Type }\end{array}$ & Blocks & $\begin{array}{l}\text { Sodium } \\
\text { Alginate } \\
(\mathbf{m g})\end{array}$ & $\begin{array}{l}\text { Chitosan } \\
(\mathbf{m g})\end{array}$ & $\begin{array}{l}\text { PEG } \\
\mathbf{4 0 0} \\
(\mathbf{m l})\end{array}$ & $\begin{array}{l}\text { Dissolution } \\
\text { in } \mathbf{1} \text { hour }\end{array}$ & $\begin{array}{l}\text { Folding } \\
\text { Endurance }\end{array}$ & $\begin{array}{l}\text { Mucoadhesion } \\
\text { force (g) }\end{array}$ \\
\hline 5 & 1 & 1 & 1 & 750 & 250 & 10 & 34.1 & 406 & 486 \\
\hline 6 & 2 & 1 & 1 & 750 & 250 & 20 & 37.5 & 449 & 493 \\
\hline 8 & 3 & 1 & 1 & 750 & 350 & 20 & 28.5 & 486 & 523 \\
\hline 7 & 4 & 1 & 1 & 750 & 350 & 10 & 26.3 & 462 & 515 \\
\hline 4 & 5 & 1 & 1 & 650 & 350 & 20 & 30.5 & 409 & 496 \\
\hline 2 & 6 & 1 & 1 & 650 & 250 & 20 & 43.6 & 386 & 323 \\
\hline 3 & 7 & 1 & 1 & 650 & 350 & 10 & 28.2 & 400 & 471 \\
\hline 1 & 8 & 1 & 1 & 650 & 250 & 10 & 40.8 & 371 & 310 \\
\hline
\end{tabular}


The above table data fitted into Minitab 16 DOE software and the ANOVA table, Factorial plots and Main effect plots with interaction effect was generated for all three responses.

Multilevel Factorial Design

\begin{tabular}{|l|l|}
\hline Factors:3 & Replicates: 1 \\
\hline Base Runs:8 & Total runs:8 \\
\hline Base Blocks:1 & Total blocks: 1 \\
\hline
\end{tabular}

Number of levels: 2, 2, 2.

Table 21 ANOVA Table for Dissolution in 1 hour

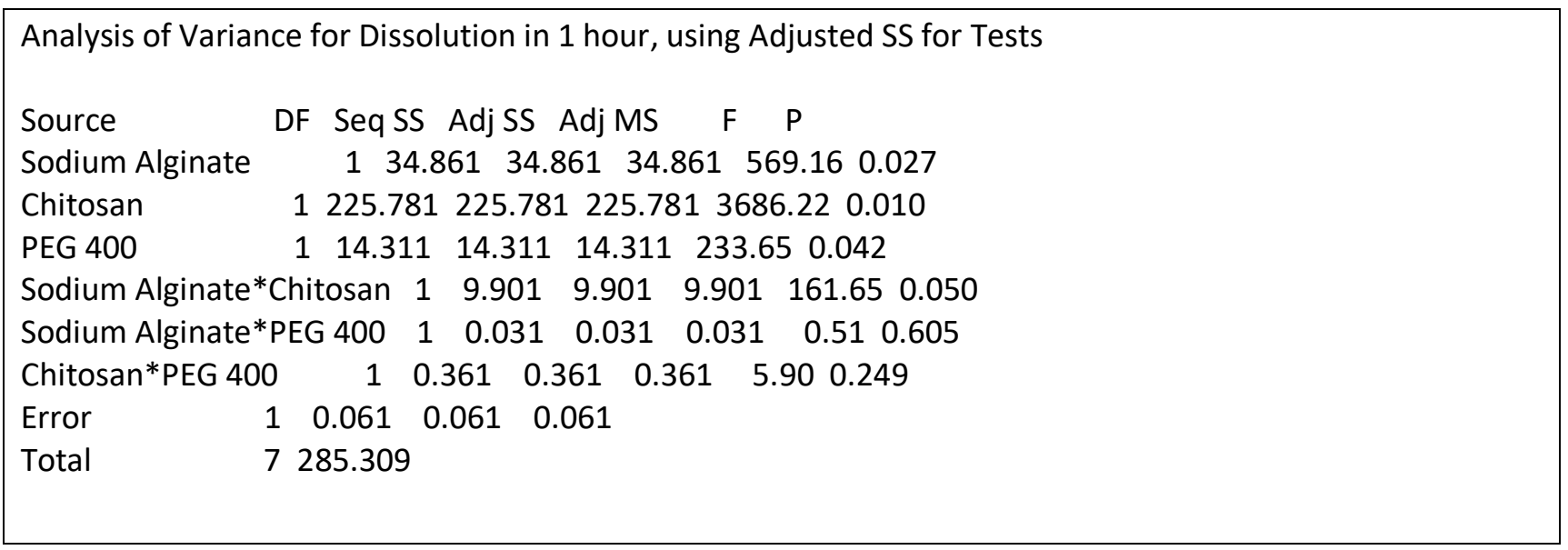

Based on P values, Sodium Alginate, Chitosan and PEG 400 all three factors found significant because the P value was less than 0.05 . All three interaction found non significant.

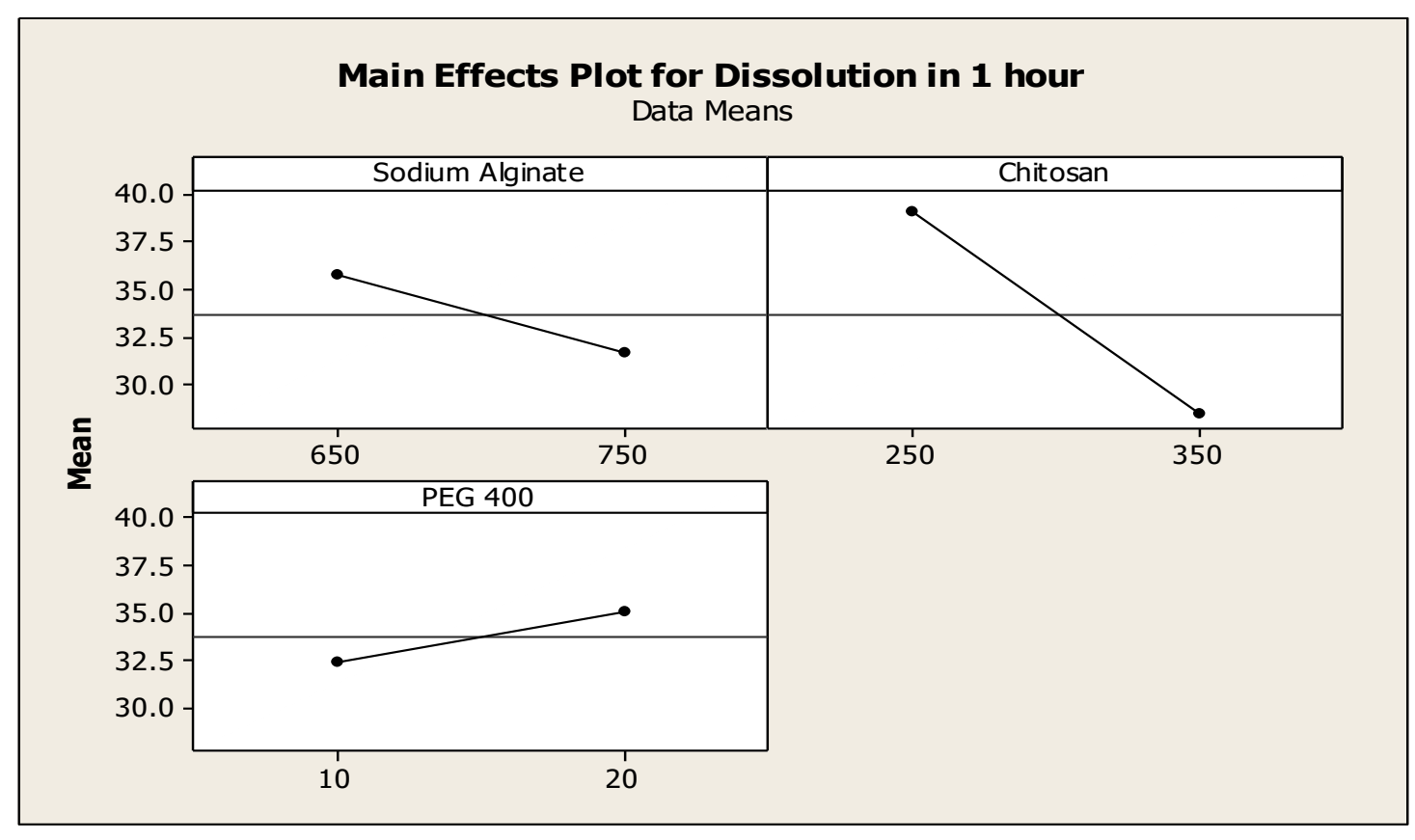

Figure 12: Main effect plots for Dissolution in 1 hour 


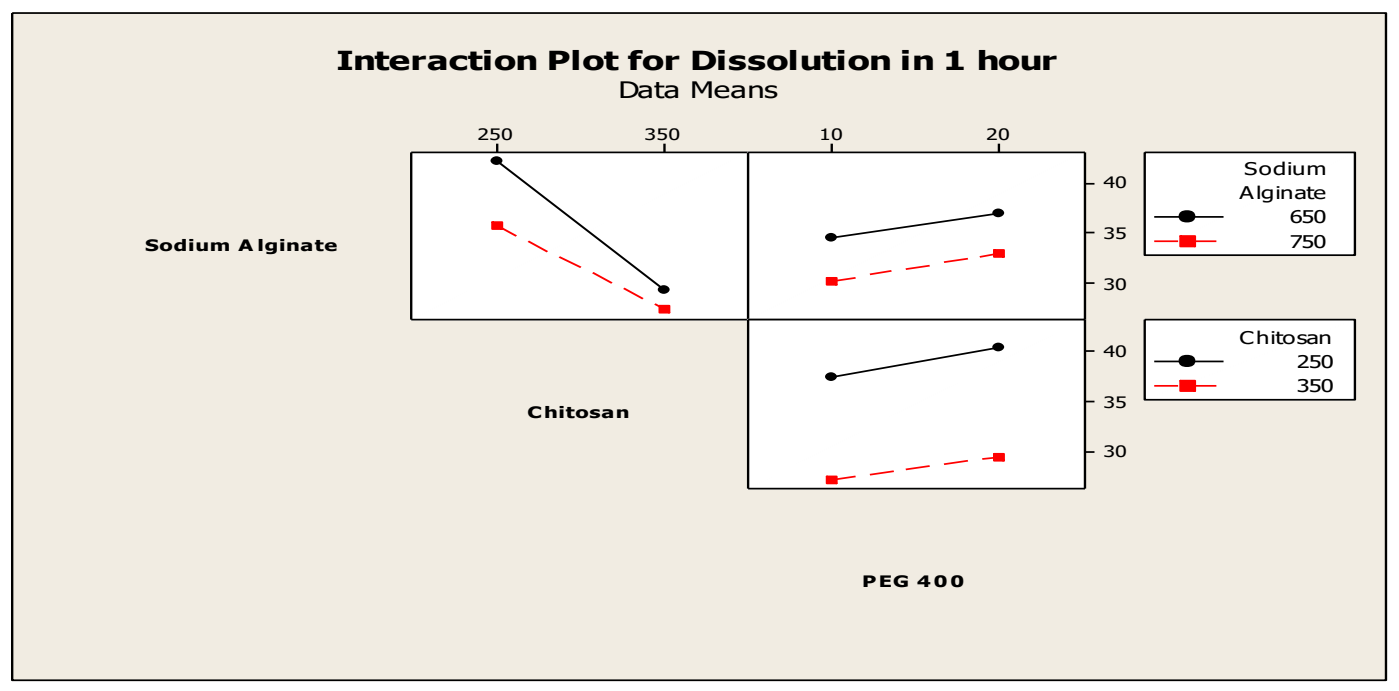

Figure 13 Interaction plots for Dissolution in 1 hour

Surface Plot of Dissolution in 1 hour vs Chitosan, Sodium Alginate

Dissolution in 1 hour

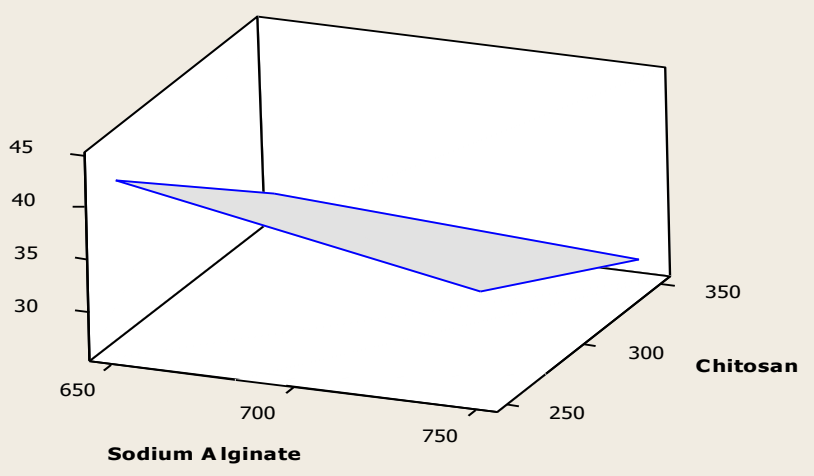

Figure 14 Surface plots for Dissolution in 1 hour

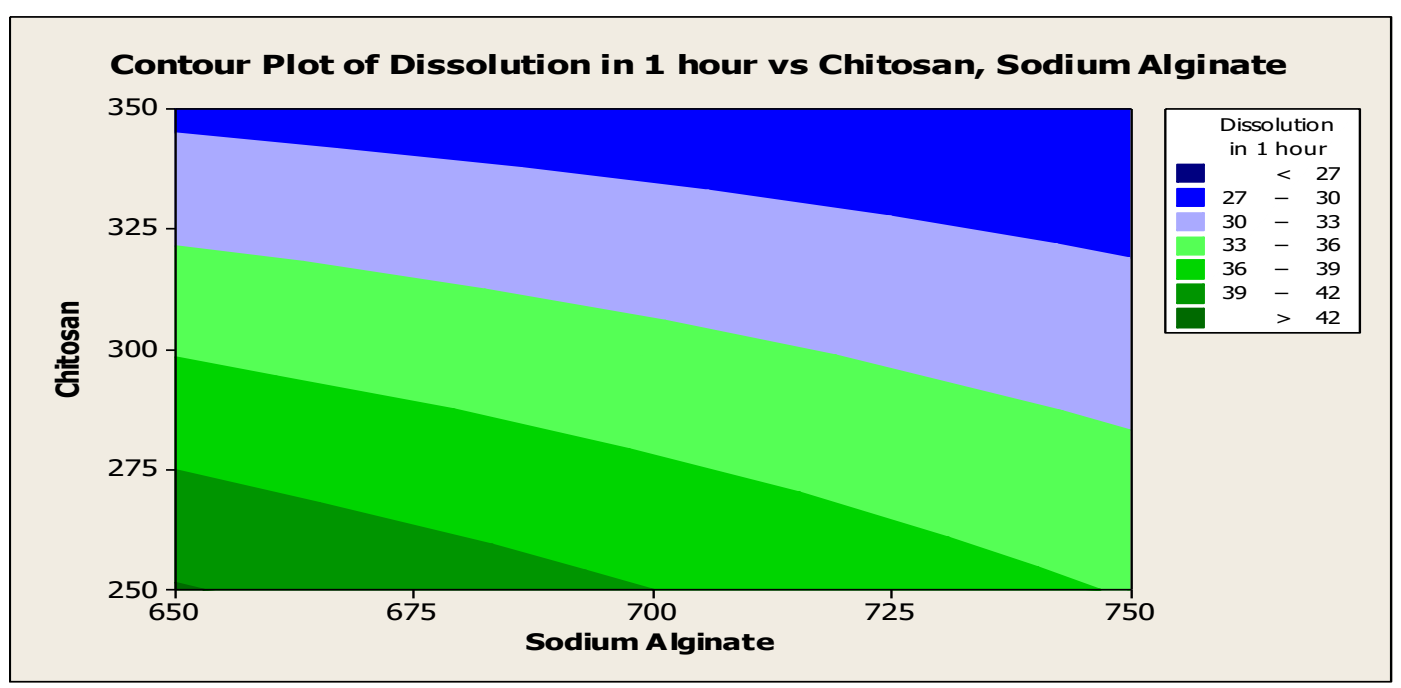

Figure 15 Contour plots for Dissolution in 1 hour 
Table 22 ANOVA Table for Folding Endurance

Analysis of Variance for Folding Endurance, using Adjusted SS for Tests

Source DF Seq SS AdjSS Adj MS F P

Sodium Alginate $\quad 17021.17021 .17021 .1332 .360 .035$

$\begin{array}{lllllllll}\text { Chitosan } & 1 & 2628.1 & 2628.12628 .1 & 124.41 & 0.057\end{array}$

$\begin{array}{llllllll}\text { PEG } 400 & 1 & 1035.1 & 1035.1 & 1035.1 & 49.00 & 0.090\end{array}$

Sodium Alginate*Chitosan $1 \quad 210.1210 .1210 .1 \quad 9.950 .195$

Sodium Alginate*PEG $400 \quad 1 \quad 231.1 \quad 231.1 \quad 231.1 \quad 10.94 \quad 0.187$

Chitosan*PEG $400 \quad 1178.1 \quad 78.1 \quad 78.1 \quad 3.70 \quad 0.305$

$\begin{array}{lllll}\text { Error } & 1 & 21.1 & 21.1 & 21.1\end{array}$

Total $\quad 711224.9$

Based on P values, only Sodium Alginate found significant because the P value was less than 0.05 . All three interactions, Chitosan and PEG 400 found non significant.

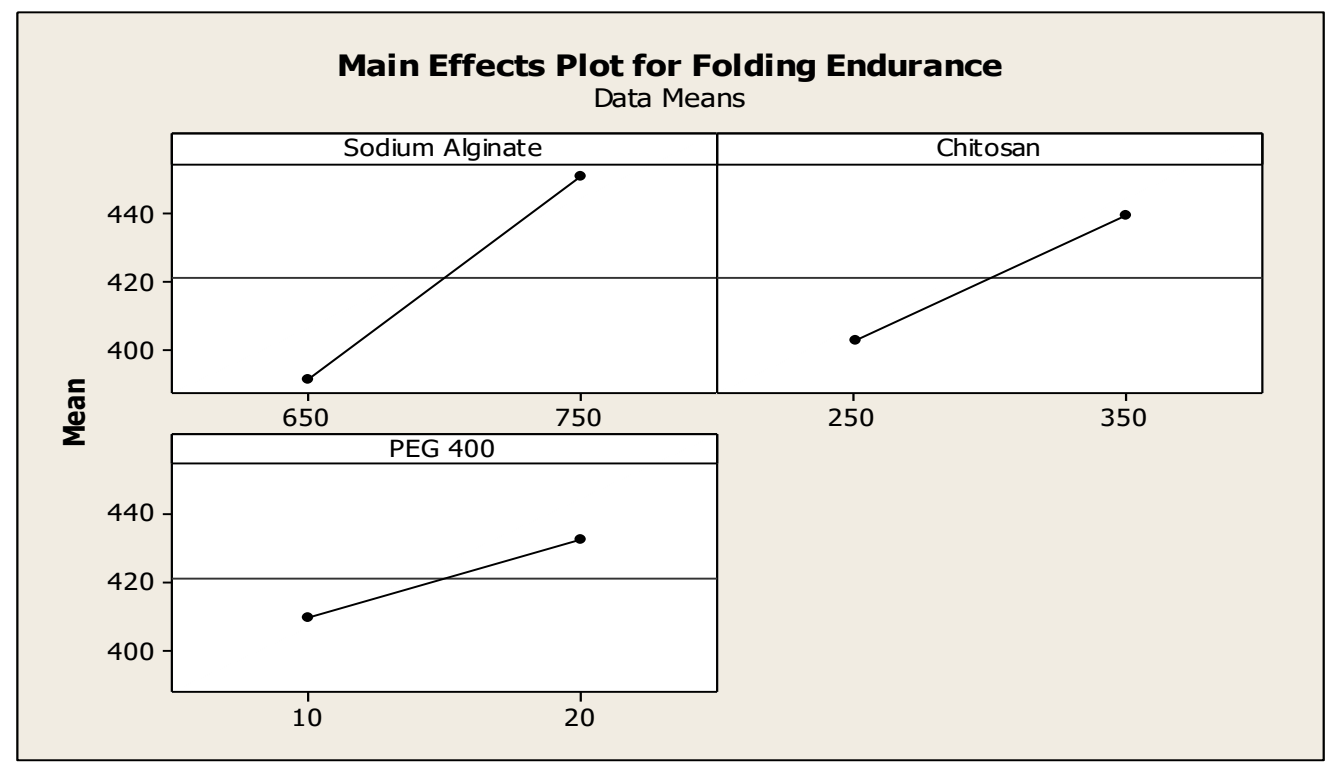

Figure 16: Main effect plots for folding endurance

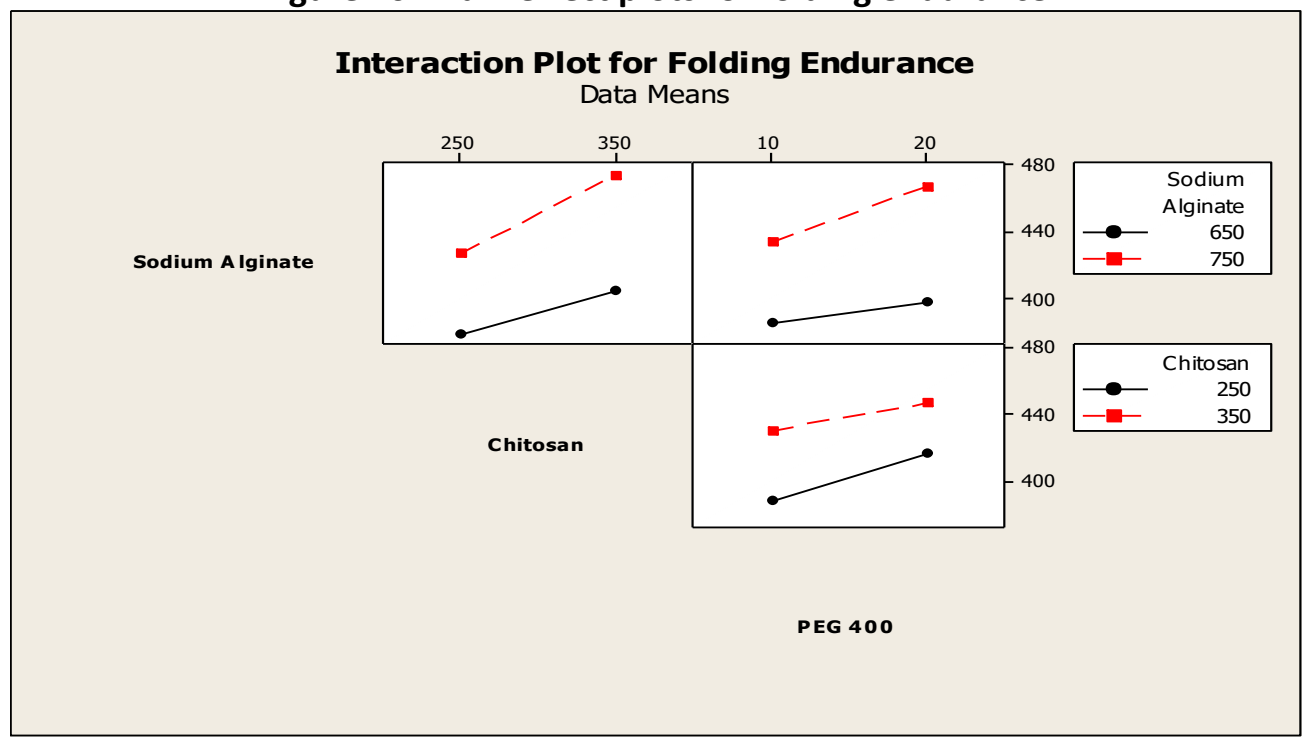

Figure 17: Interaction plots for folding endurance 


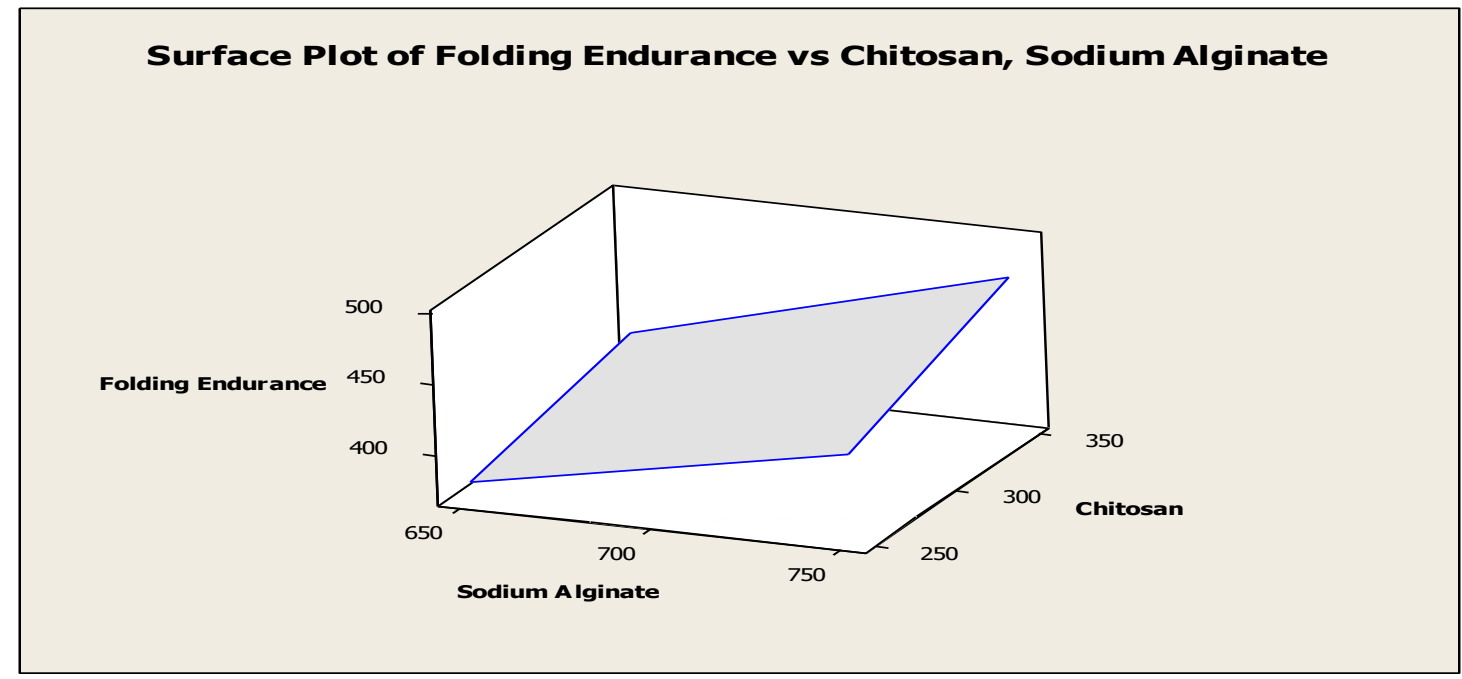

Figure 18: Surface plots for folding endurance

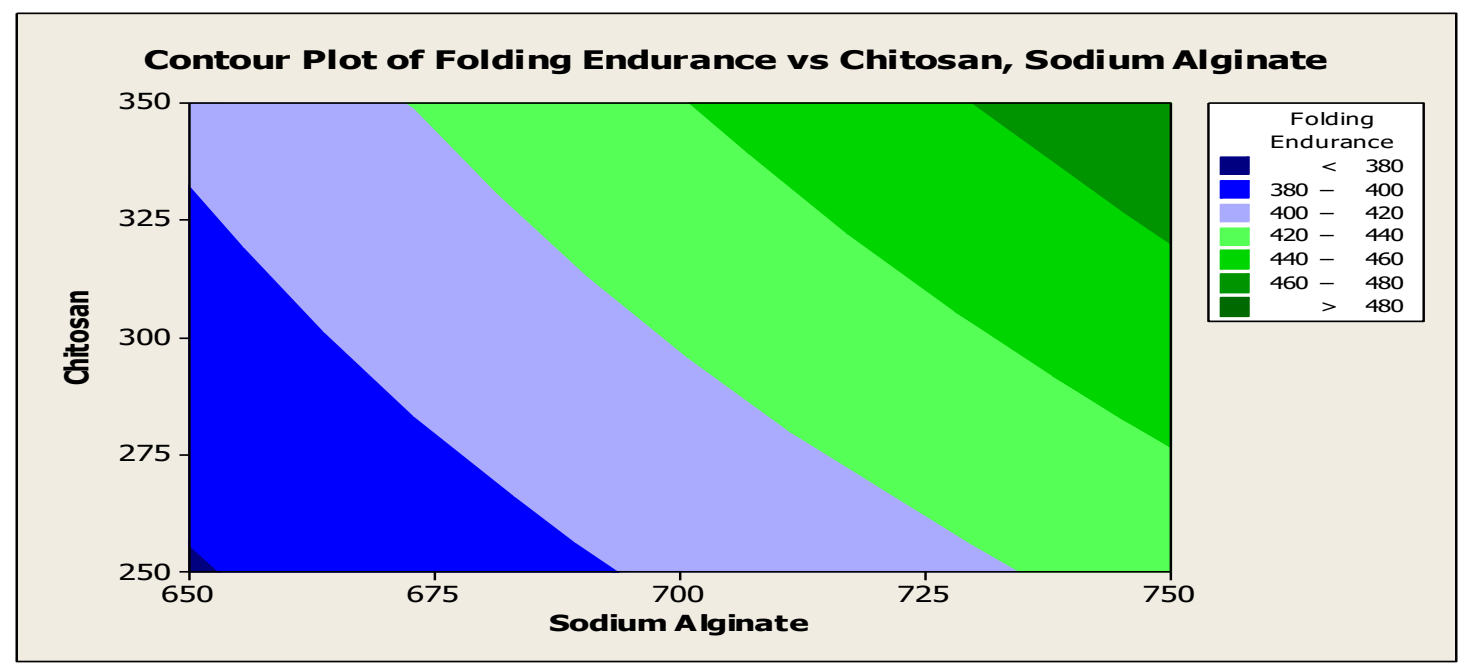

Figure 19: Contour plots for folding endurance

Table 23 ANOVA Table for Mucoadhesion force

Analysis of Variance for Mucoadhesion force (g), using Adjusted SS for Tests

\begin{tabular}{lrrrrrrlll} 
Source & DF & Seq SS & Adj SS & Adj MS & $F$ & $P$ \\
Sodium Alginate & \multicolumn{1}{l}{1} & 21736.1 & 21736.1 & 21736.1 & 1437.10 & 0.017 \\
Chitosan & 1 & 19306.1 & 19306.1 & 19306.1 & 1276.44 & 0.018 \\
PEG 400 & 1 & 351.1 & 351.1 & 351.1 & 23.21 & 0.130 & \\
Sodium Alginate*Chitosan & 1 & 9453.1 & 9453.1 & 9453.1 & 625.00 & 0.025 \\
Sodium Alginate*PEG & 400 & 1 & 66.1 & 66.1 & 66.1 & 4.37 & 0.284 \\
Chitosan*PEG & 400 & 1 & 21.1 & 21.1 & 21.1 & 1.40 & 0.447 \\
Error & 1 & 15.1 & 15.1 & 15.1 & & & & \\
Total & 7 & 50948.9 & & & & & &
\end{tabular}

Based on P values, Chitosan and Sodium Alginate found significant because the P value was less than 0.05 . Sodium Alginate and Chitosan interaction also found significant. All other interactions and PEG 400 found non significant. 


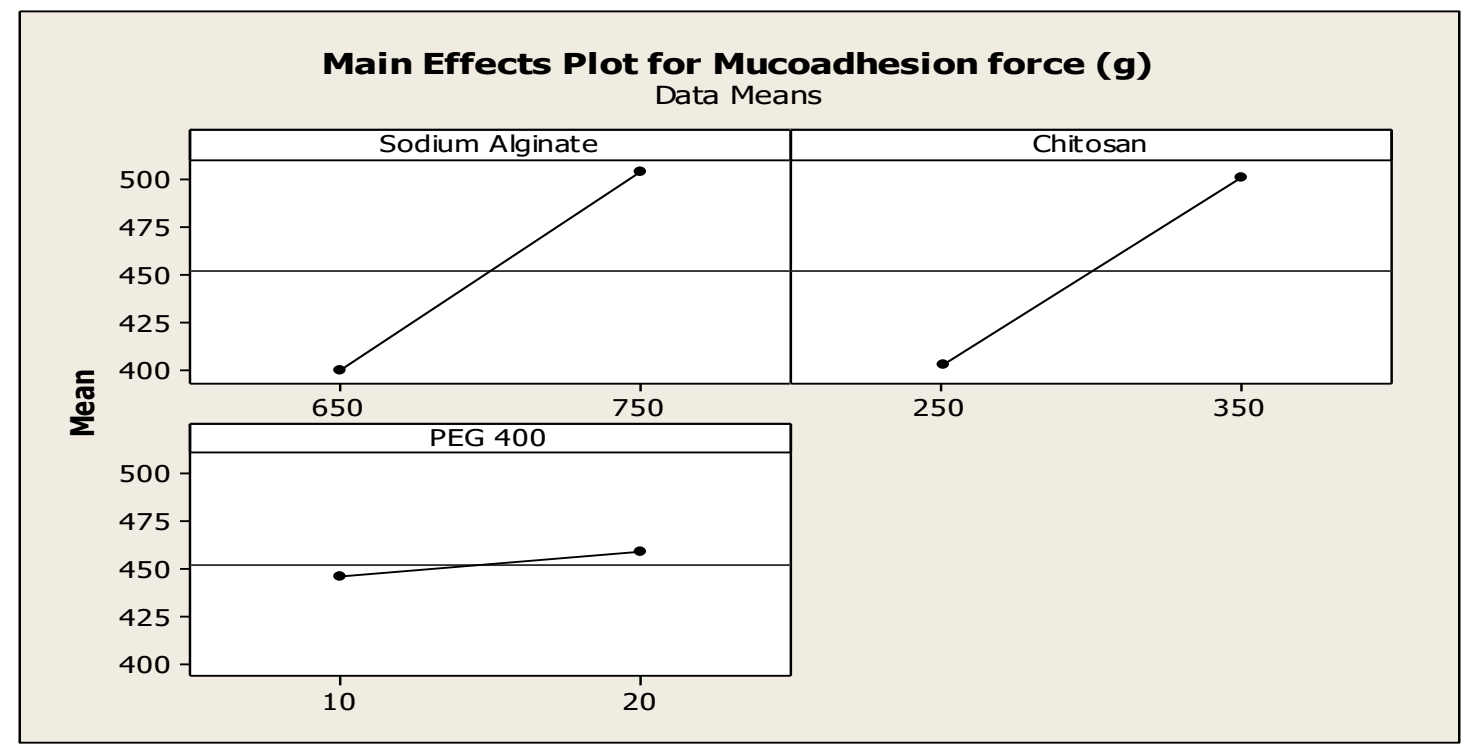

Figure 20: Main effects plots for Mucoadhesion Force

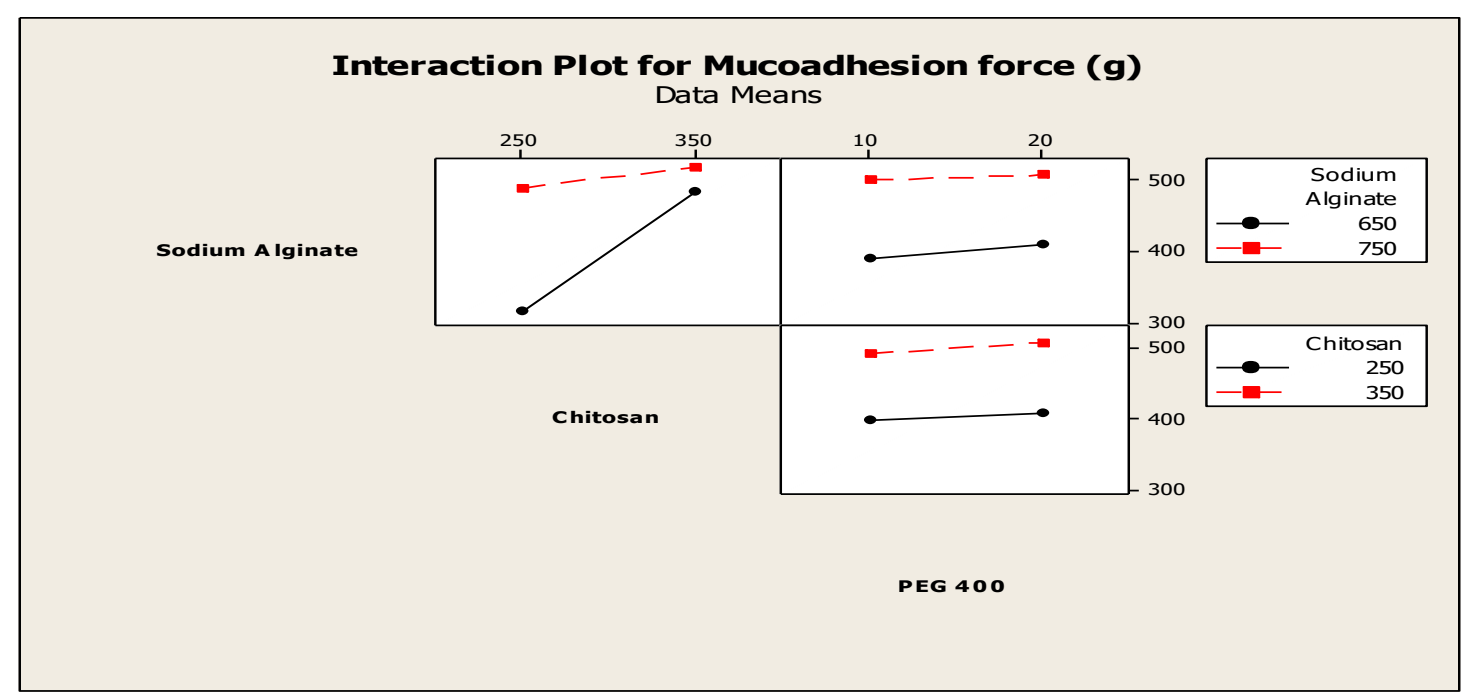

Figure 21: Interaction plots for Mucoadhesion Force

Surface Plot of Mucoadhesion force (g) vs Chitosan, Sodium Alginate

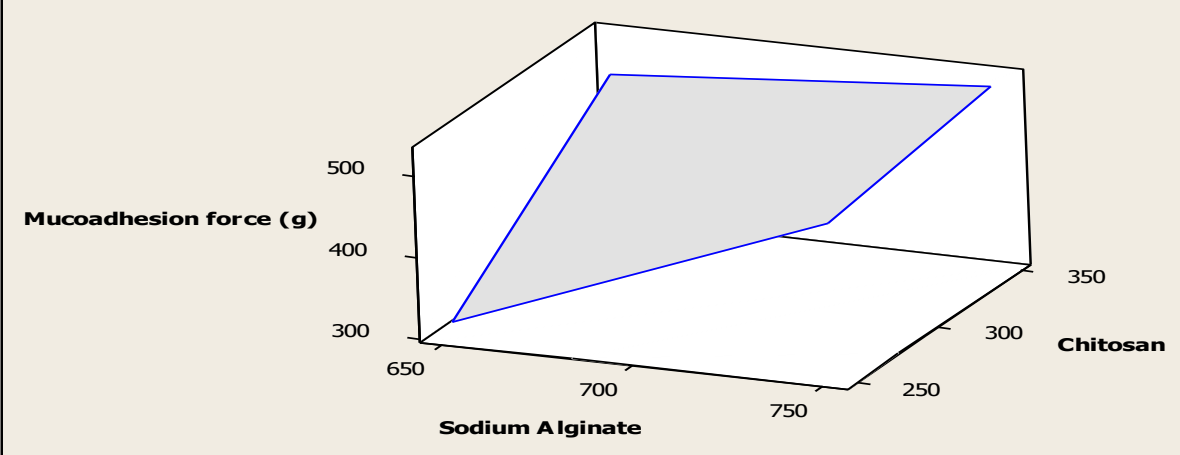

Figure 22 Surface plot for Mucoadhesion Force 


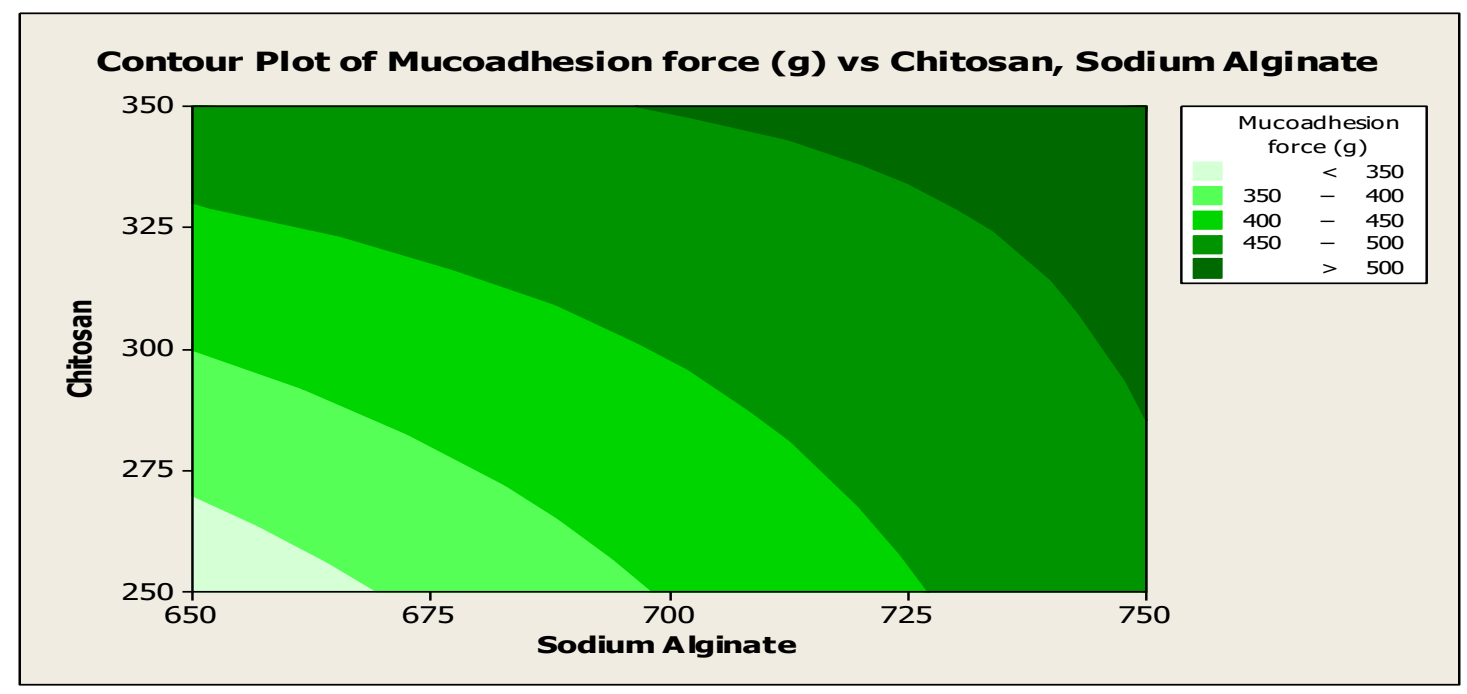

Figure 23: Contour plot for Mucoadhesion Force

\subsection{STABILITY STUDY}

Optimized batch F9 was selected for stability study and 1 month stability study was performed at 40 ${ }^{\circ} \mathrm{C} / 75 \% \mathrm{RH}$ as per $\mathrm{ICH}$ guideline. Initial and 1 month results were recorded below. Based on one month stability study data, F9 batch found stable.

Table 24: Stability study of F9 batch

\begin{tabular}{|l|l|l|}
\hline Parameters & Initial Results & After 1 month results \\
\hline Drug Content (\%) & $99.2 \pm 2.3$ & $98.9 \pm 3.5$ \\
\hline Folding Endurance & $409 \pm 21$ & $407 \pm 16$ \\
\hline Surface pH & $6.8 \pm 0.4$ & $6.9 \pm 0.3$ \\
\hline Drug release at 8 hour & $99.1 \pm 0.5$ & \pm 0.9 \\
\hline
\end{tabular}

\section{CONCLUSION}

The main objective of the study was to formulate and evaluate sustained release buccal film containing Saxagliptin. Buccal films were prepared by solvent casting method without using any organic solvents. Compatibility of Saxagliptin with polymer was confirmed by FTIR study. Prepared films were analyzed for various parameters like physical Weight variation, thickness, folding endurance, drug content, tensile strength, \% elongation and \% Drug release. From the all formulations F1-F4, formulation F4 which contain $750 \mathrm{mg}$ of Sodium Alginate and $250 \mathrm{mg}$ Chitosan was optimized because it gives maximum drug release up to $8 \mathrm{hr}$. Based on F4 formulation, factorial design was be planned by taking Sodium Alginate, Chitosan and PEG 400 as independent variables for $2^{3}$ factorial design. From the factorial batches the F9 batch which gives most satisfactory drug release with respect to targeted drug release profile was selected as optimized batch. The mucoadhesion properties were also found satisfactory in F9 formulation. Folding endurance was 
more than 400. Dissolution data of F9 batch fitted in kinetic models and higuchi model was found best fitted model among all as its $\mathrm{R}^{2}$ was 0.990 . Formulation F9 was found stable during 1 month stability study.

\section{REFERENCES}

1. Mamatha V, Prasanth V, Selvi A, Sipai A, "Buccal Drug Delivery: A Technical Approach," J. Drug Deliv. Ther, 2012, 2 (2), 26-33.

2. S. Barua, "Drug delivery techniques for buccal route: formulation strategies and recent advances in dosage form design," J. Pharm. Investig, 2016, 46 (7), 593-613,

3. Caon, L. Jin, C. Simoes, R, and Nicolazzo J, "Enhancing the buccal mucosal delivery of peptide and protein therapeutics," Pharm. Res., 2015, 32 (1), 1-21.

4. Arun J, Rani S and Manoj K, "Buccal drug delivery system: History and recent developments," Asian J. Pharm. Clin. Res., 2016, 9 (6), 36-42.

5. Boddupalli Z, Mohammed R and Banji D, "Mucoadhesive drug delivery system: An overview," J. Adv. Pharm. Technol. Res., 2010, 1(4), 381-390.

6. Farhan Ahmed, Gaurav. Jain. In Lachman Lieberman's The Theory and Practice of Industrial Pharmacy 4th edition. 2013, 483.

7. Gandhi S, Pandya P, Umbarkar R and Tambawala T, "Mucoadhesive Drug Delivery Systems-an Unusual Maneuver for Site Specific Drug Delivery System," Pharma Sci. Monit. An Int. J. Pharm. Sci., 2011, 2 (3), 132-152.

8. Jain NK. Progress in controlled and novel drug delivery systems Delhi, CBS Publishers. 2003, 76- 97.

9. Brahmankar DM \& Jaiswal SB. Biopharmaceutics and pharmacokinetics a treatise. Vallabh Prakashan, 2008, 337.

10. R. Mujoriya, K. Dhamande, U. Washkhede, and S. Angure, "A review on study of buccal drug delivery system," Innov. Syst. Des. Eng., 2011, 2 (3), 200-204.

11. Patel K, Dodiya $H$, Shelat $P$, "Buccal Bioadhesive drug delivery system: An overview", Inter J of Pharma bio. 2011, 2(2), 600-609.

12. Patel $M$, Savaliya $P$, Ramma $M$, "Buccal drug delivery system." International research journal of pharmacy, 2011, 2(2), 4-11.

13. Disease Information, October 2018: - https://www.mayoclinic.org/diseases-conditions/ diabetes/symptoms-causes/syc-20371444.

14. Drug Information, October 2018: - https://www.drugbank.ca/drugs/DB06335.

15. Drug Information, October 2018: - https://pubchem.ncbi.nlm.nih.gov/compound/Saxagliptin.

16. Drug Information, October 2018: - https://en.wikipedia.org/wiki/Saxagliptin.

17. Drug Information, October 2018: - https://www.rxlist.com/onglyza-drug.htm.

18. Drug Information, October 2018: - https://medlineplus.gov/druginfo/meds/a610003.html.

19. Drug Information, October 2018: - https://livertox.nih.gov/Saxagliptin.htm.

20. Drug Information, October 2018:- https://www.webmd.com/drugs/2/drug-152751/ saxagliptinoral/details

21. Puja S, Pratik S, "Formulation Development and Evaluation of Buccal Patches of Aceclofenacfor Gingivitis", RJPDFT, 2017, 9 (4), 1-5.

22. Ashutosh $R$, Prabhakara $P$, Akhilesh $D$, "Design And Evaluation of Buccal Patches Containing Combination of Hydrochlorothiazide and Atenolol", Int J App Pharm, 2018, 10 (2), 105-112.

23. Sahar S, Soheil B, "New formulation and approach for mucoadhesive buccal film of rizatriptan benzoate", Prog Biomater, 2017, 6, 175-187.

24. Rahul S, Anilkumar J, Deepti $S$ and Harinath N, "Formulation, Design and Characterization of Mucoadhesive Buccal Film of Nebivolol Using Factorial Design", IJPSR, 2018, 9 (5), 1797-1805.

25. Chengliang Z, Yanan L, Wei L, Ping G, Dong X, Xiuhua R \& Dong L, "Mucoadhesive buccal film containing ornidazole and dexamethasone for oral ulcers: in vitro and in vivo studies", Pharmaceutical Development And Technology, 2018, 1-10.

26. Pooja S, Dharmendra S, "Formulation and Evaluation of Mucoadhesive Buccal Patch of Timolol Maleate", Am. J. PharmTech Res. 2017, 7(2), 335-348. 
27. Ali R, Cetin $T$, Ayhan S, Yalcin $O$ and Tamer B, "Delivery of Piroxicam With A Mucoadhesive Buccal Tablet: In Vitro, Ex Vivo and In Vivo Evaluation", Research and Reviews: Journal of Pharmacy and Pharmaceutical Sciences, 2016, 5 (1), 33-44.

28. Rohan M, Subhajit G, Surajpal V, Bhupendra S, Manish V2, Meenu M, Anzarul H, "Polymers in designing the mucoadhesive films: A comprehensive review", International Journal of Green Pharmacy, 2018, 12 (2), S330-S344.

29. Balakrishna $T$, Vidyadhara $S$, Murthy $T$, Sasidhar R, "Formulation and Evaluation of Lansoprazole Fast Dissolving Buccal Films", Asian Journal of Pharmaceutics , 2018, 12 (2), S728-S735.

30. Rajesh S, Poddar S, "Development and Characterization of Mucoadhesive Buccal Patches of Salbutamol Sulphate", Current Drug Delivery, 2009, 6, 140-144.

31. Talat F, Azmat S and Sadhana S, "Formulation Development of Mucoadhesive Microspheres of antidiabetic Drug", World Journal of Pharmaceutical Research, 2018, 7 (1), 1549-1561.

32. Iswariya V, Hariom P, Lokeswara B, Srinivasa R, "Formulation and Evaluation of Oro Dispersive Tablets of Saxagliptin", Int. J. Pharm. Sci. Rev. Res., 2015, 30 (2), 230-234.

33. Shubhangi C, Madhumita A, Sanjay G and Mahendra K, "Quality by Design Approach for The Development And Validation of Saxagliptin By RP-HPLC With Application to Formulated Forms", IJPSR, 2016, 7(4), 1670-1677.

34. Margret C, Palanisamy P, Jaykar B, Venkateswarlu B, Pasupathi A, "Formulation and Evaluation of Saxagliptin Immediate Release and Metformin Hydrochloride Sustained Release Tablet", International Journal of Health Sciences, 2013, 1(1), 36-52.

35. Kalaichelvi R and Jayachandran E., "Validated Spectroscopic Method For Estimation of Saxagliptin In Pure And From Tablet Formulation", Int J Pharm Pharm Sci, 2011, 3 (3), 179-180. 